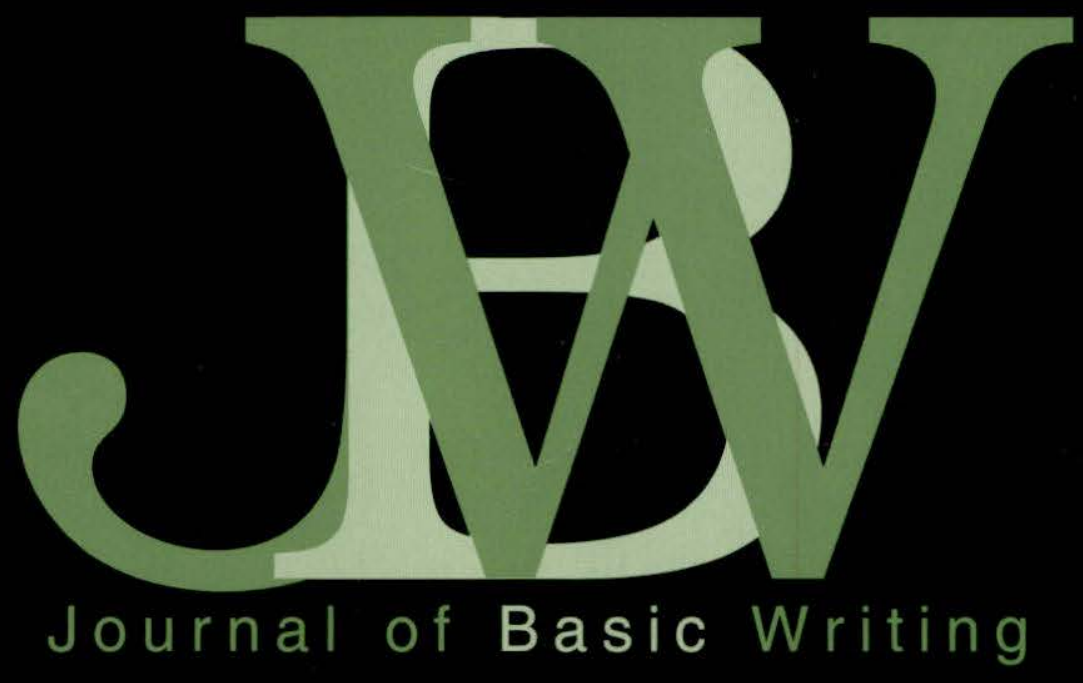

Teaching and Learning in Texas:

Accountability Testing, Language, Race, and Place

Susan Naomi Bernstein

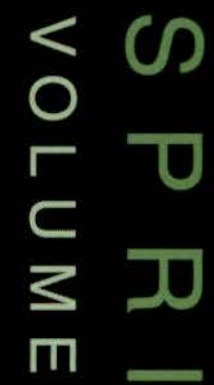

Study of Teacher Error:

Misreading Resistance in the Basic Writing Classroom

Sara Biggs Chaney

N

Rethinking Language and Culture on the

$\omega$ Institutional Borderlands

\title{
Virginia Crisco
}

Paradigm Clashes Among. Basic Writing Teachers:

Sources of Conflict and a Call for Change

\section{Ann Del Principe}

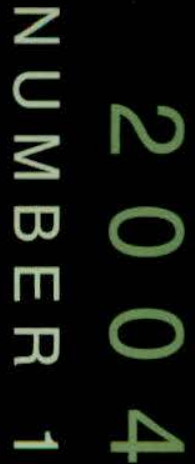

"You Probably Don't Even Know I Exist":

Notes from a College Prison Program 


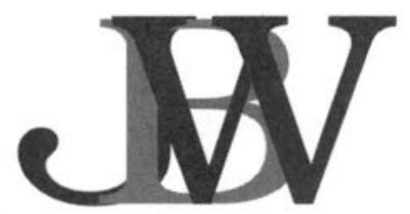

Journal of Basic Writing

VOLUME 23

The Journal of Basic Writing publishes articles of theory, research, and teaching practices related to basic writing. Articles are refereed by members of the Editorial Board (see overleaf) and the Editors.

\title{
Bonne August and Rebecca Mlynarczyk Editors
}

\section{Johannah Rodgers and Karen Weingarten} Editorial Assistants

The Journal of Basic Writing is published twice a year, in the spring and fall with support from the City University of New York, Office of Academic Affairs. We welcome unsolicited manuscripts and ask authors to consult the detailed "Call for Articles" in this issue. Subscriptions for individuals are $\$ 15.00$ for one year and $\$ 28.00$ for two years; subscriptions for institutions are $\$ 20.00$ for one year and $\$ 38.00$ for two years. Foreign postage is $\$ 10.00$ extra per year. For subscription inquiries or updates, contact:

\author{
Journal of Basic Writing \\ Boyd Printing Company, Inc. \\ Attn. Cathie Ryan \\ 49 Sheridan Ave. \\ Albany, NY 12210 \\ (800) $877-2693$ \\ (518) 436-9686 \\ www.boydprinting.com
}

Published by the City University of New York since 1975

Cover and logo design by Kimon Frank

Copyright $(2004$ by the Journal of Basic Writing ISSN 0147-1635 


\title{
JOURNAL OF BASIC WRITING
}

\author{
EDITORIAL BOARD
}

\author{
Linda Adler-Kassner \\ Eastern Michigan University \\ Chris M. Anson \\ North Carolina State University \\ David Bartholomae \\ University of Pittsburgh \\ Sarah Benesch \\ College of Staten Island, CUNY \\ Patricia Bizzell \\ College of the Holy Cross \\ Lynn Z. Bloom \\ University of Connecticut, Storrs
}

Gay Brookes
Borough of Manhattan Community
College, CUNY

Richard Courage

Westchester Community College,

SUNY

Martha Clark Cummings

University of Aizu, Japan

Donald A. Daiker

Miami University

\section{Suellynn Duffey}

Georgia Southern University

Sarah Warshauer Freedman

University of California, Berkeley

Keith Gilyard

Pennsylvania State University

Gregory Glau

Arizona State University

Laura Gray-Rosendale

Northern Arizona University

Karen L. Greenberg

Hunter College, CUNY

Brenda M. Greene

Medgar Evers College, CUNY

Myra Kogen

Brooklyn College, CUNY

Patricia O. Laurence

City College, CUNY
Andrea A. Lunsford

Stanford University

Jane Maher

Nassau Community College, SUNY

Susan Miller

University of Utah

Sandra Murphy

University of California, Davis

Deborah Mutnick

Long Island University

Nathaniel Norment, Jr.

Temple University

George Otte

Graduate Center, CUNY

Hope Parisi

Kingsborough Community College,

CUNY

Elizabeth Rorschach

City College, CUNY

Charles I. Schuster

University of Wisconsin, Milwaukee

Tony Silva

Purdue University

Trudy Smoke

Hunter College, CUNY

Ruth Spack

Bentley College

Lynn Quitman Troyka

Queensborough Community

College, CUNY, ret.

Karen S. Uehling

Boise State University

Evelyn E. Webb

Mississippi State Board for

Community and Junior Colleges

Harvey S. Wiener

Laguardia Community College,

Emeritus

Vivian Zamel

University of Massachusetts,

Boston 


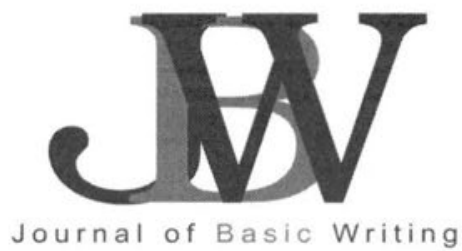

Journal of Basic Writing

\section{VOLUME 23

Editors' Column

Teaching and Learning in Texas:

Accountability Testing, Language, Race, and Place

Susan Naomi Bernstein

4

Study of Teacher Error:

Misreading Resistance in the Basic Writing Classroom

Sara Biggs Chaney

Rethinking Language and Culture on the Institutional Borderland

Virginia Crisco

Paradigm Clashes Among Basic Writing Teachers:

Sources of Conflict and a Call for Change

Ann Del Principe

64

"You Probably Don't Even Know I Exist":

Notes from a College Prison Program

Jane Maher

82

News and Announcements 


\section{CALL FOR ARTICLES}

We welcome manuscripts of 15 -25 pages, double spaced, on topics related to basic and ESL writing, broadly interpreted. Submissions should follow current MLA guidelines. Manuscripts are refereed anonymously. To assure impartial review, include name(s), affiliation(s), mailing and e-mail addresses, and a short biographical note for publication on the cover page only. The second page should include the title but no author identification, an abstract of about 150 words, and a list of $4-5$ key words. Endnotes should be kept to a minimum. It is the author's responsibility to obtain permission for including excerpts from student writing.

We prefer that contributions be submitted as Word document attachments via email to: baugust@kbcc.cuny.edu. If electronic submission is not possible, mail five copies of the manuscript and abstract to:

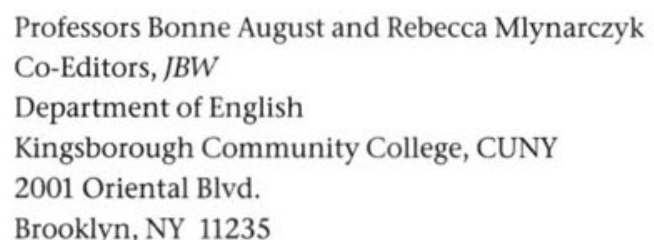

You will receive a confirmation of receipt; a report on the status of your submission will follow in about sixteen weeks.

All manuscripts must focus clearly on basic writing and must add substantively to the existing literature. We seek manuscripts that are original, stimulating, well-grounded in theory, and clearly related to practice. Work that reiterates what is known or work previously published will not be considered.

We invite authors to write about such matters as classroom practices in relation to basic-writing or second-language theory; cognitive and rhetorical theories and their relation to basic writing; social, psychological, and cultural implications of literacy; discourse theory; grammar, spelling, and error analysis; linguistics; computers and new technologies in basic writing; assessment and evaluation; writing center practices; teaching logs and the development of new methodologies; and cross-disciplinary studies combining basic writing with psychology, anthropology, journalism, and art. We publish observational studies as well as theoretical discussions on relationships between basic writing and reading, or the study of literature, or speech, or listening. The term "basic writer" is used with wide diversity today, sometimes referring to a student from a highly oral tradition with little experience in writing academic discourse, and sometimes referring to a student whose academic writing is fluent but otherwise deficient. To help readers, therefore, authors should describe clearly the student population which they are discussing.

We particularly encourage a variety of manuscripts: speculative discussions which venture fresh interpretations; essays which draw heavily on student writing as supportive evidence for new observations; research reports, written in non-technical language, which offer observations previously unknown or unsubstantiated; and collaborative writings which provocatively debate more than one side of a central controversy. 


\section{EDITORS' COLUMN}

$J B W$ began publication nearly 30 years ago. Its emergence both acknowledged the unprecedented scale of the Open Admissions project then transforming the City University of New York and other large public institutions and also extended the discussion about teaching these students, who represented a new constituency for public education. As we approach the milestone of our $30^{\text {th }}$ year of publication, we might speculate about the sense of contingency that still characterizes the field after these many years. In "Paradigm Clashes Among Basic Writing Teachers: Sources of Conflict and a Call for Change," Ann Del Principe, writing about the profound differences between basic writing teachers whose teaching has been informed by scholarship in composition and basic writing, and those who have developed their pedagogy informally and sometimes in relative isolation, concludes, "There is some irony to the fact that the majority of basic writing courses may be taught by faculty who are unfamiliar with basic writing scholarship." Indeed there is. Moreover, not only are BW faculty still likely to be self-trained, they are especially likely to be untenured faculty, graduate students, adjuncts, "part-timers"-contingent faculty in a contingent field.

Basic Writing is the field that was supposed to go away, vanish, become obsolete as soon as the schools solved the "problem" of student literacy or until state mandated testing finally succeeded in bringing everyone to the "standard." Although reasonable people might have concluded long since that BW is here to stay, something-call it wishful thinking, political expediency, or persistent delusion-continues to impel the search for a simplistic answer or a shortcut that will render basic writing unnecessary. If BW programs are to face limitations, as they have in the California State system, it is more likely because of fiscal constraints and newly imposed limits to access than to the success of testing programs or a dramatic improvement in secondary education.

Texas in many ways has led the way in articulating very specific standards and requiring statewide testing to insure that students are competent. In "Teaching and Learning in Texas: Accountability Testing, Language, Race, and Place," Susan Naomi Bernstein reminds us that Texas has provided the model not only for other states individually but for national policy as well. At the same time, she describes with considerable poignancy the situation of her Latino/a students who, despite having met the high school standard, discover when they enter college how limited their preparation and their education have been, specifically because of the pressure to teach to the tests. Bernstein's piece illustrates not only the constraints the state mandates have placed on the high school curricu- 
lum, but also the failure of the system to implement expectations for students that acknowledge or nurture the strengths they have brought with them or that challenge their capacity for intellectual growth.

Ann Del Principe's piece, "Paradigm Clashes" also considers expectations, both the constricted expectations that some BW teachers or programs have for students and the correspondingly low expectations for those hired to teach basic writing. Del Principe speaks for those teachers of courses labeled "remedial," "developmental," or "basic" (and often assigned zero credits) who conceive of their work as the beginning of students' college experience, and not as a precollege trial period. Rather than settle for the minimum competence often encouraged by standardized tests, they design curriculum characterized by rigor, intellectual challenge, and high expectations, as well as by carefully structured scaffolding and support. Del Principe considers the substantial obstacles to making this approach the norm, and while she is unable to offer a conclusive solution, she offers a deeply felt and strongly argued statement of the problem.

Both Virginia Crisco in "Rethinking Language and Culture on the Institutional Borderland" and Sara Biggs Chaney in "A Study of Teacher Error: Misreading Resistance in the Basic Writing Classroom" discuss expectations with an eye to repositioning students in the institution so that they may not only assume genuine authority over their own education but also have a discernible impact on the institution and the experience of students overall. Like Bernstein, Crisco looks specifically at a Latino/a population, while Chaney's essay moves from a case study of a resistant student to a more general analysis of the place colleges and universities assign to students and the possibilities for repositioning them.

Jane Maher's subject, teaching in a women's prison, involves the most complex and controlling set of physical and psychological constraints. Maher describes students whose lives, even before prison, were subject to the buffeting of every imaginable negative force, and who now experience almost total control by their environment. Still, here where expectations might be the lowest, education can be, as Maher demonstrates, truly transformative.

Like Bernstein's piece, these essays by Crisco, Chaney, and Maher show students reflecting on their own education, as well as on their goals, their learning, and the obstacles to learning. In many ways, Basic Writing as a field has moved from dependence on a set program of study to a recognition that students need to engage the process, as Chaney, Crisco, and Bernstein argue. In a way, we have resisted the enforced contingency that characterizes BW programs by embracing instead a deliberate contingency in our theorizing. This is not because we lack knowledge, but rather because we now understand the need to 
make room in the work for the students, not only as objects but instead as subjects, as actors, as players in our curriculum, pedagogy, and institutions. The making of knowledge in composition, to use Stephen North's, term, has become the work not only of teachers but also of students. Exactly how to accomplish this in any one specific setting or situation is, we now understand, not fixed but to some degree contingent. More than 20 years ago, Ira Shor began to argue for student empowerment and attempted to persuade teachers that transferring power in the classroom made learning possible. As Virginia Crisco in this issue and Laura Gray-Rosendale and her co-authors in an earlier issue (22.1, Spring 2003) have shown, however, the way to accomplish this transfer and the learning that it enables is not always and everywhere the same. Students' cultures, besides their immediate effect on the students themselves, affect the classroom profoundly. Our work needs to acknowledge this reality. Seen this way, contingency becomes a strength-an enabling constraint.

Sounding once again the theme of constraints and expectations but turning for a moment to this journal, we are happy to announce-although readers have surely already observed-the debut of the first stage of $J B W$ 's new cover and interior design. Looking for a way to update the appearance of $J B W$ but constrained by limited funds, we asked Judith Wilde, who directs the Graphic Design Program here at Kingsborough Community College, if students in the program might be given the task of redesigning the cover and logo as a class assignment. After some discussion of constraints and expectations, Professor Wilde and Olga Mezhibovskaya, an instructor in the program who had actually begun her Kingsborough career as a new immigrant in our ESL program, presented the assignment to their students. We found many of the designs appealing, but finally chose Kimon Frank's because it seemed to characterize the fresh, slightly edgy quality we were looking for. To Kimon Frank, the student designer whose work was selected-and who, coincidentally, had been a successful student in KCC's basic writing program-our admiration and thanks.

\section{-Bonne August and Rebecca Mlynarczyk}




\title{
Teaching and Learning in Texas: Accountability Testing, Language, Race, and Place
}

\author{
Susan Naomi Bernstein
}

ABSTRACT: This article examines education law and cultural conditions for teaching and learning in Texas, the state that provided a model for the federal No Child Left Behind Act signed in 2002. Accountability testing is a primary feature of Texas education law and has an enormous impact on public school culture. Of particular interest is Houston, one of the largest cities in the US, where more than half of public school students are identified by the school district as English language learners. The article investigates how students enrolled in a developmental English course use their own writing to advocate for change. The students attend an urban, Hispanic-serving, open admissions university and often are described as Generation 1.5. In particular, the article focuses on the case study of one student and his response to being identified as an English language learner.

\section{Introduction}

My study begins with the cultural and legal contexts of teaching in Texas. Yet it seems insufficient merely to document how state law and cultural conflicts influence our teaching here. Instead, I use this background to describe teaching basic writing not as an act of either enculturation or resistance, but as an active process that both uncovers systemic issues that affect our students and also facilitates an opportunity for students to speak back to those issues and to discover new methods and models more conducive to undertaking their own preparation for college-level writing. As part of this investigation, I focus on a Fall 2003 semester basic writing and reading class that chose "education" as its generative theme (Shor). In particular, I concentrate on the story of Noah, a Latino student, (whose name I have changed to protect privacy), and his struggles with systemic inequality in Texas public schools. Rather than paint Noah as a victim of circum-

Susan Naomi Bernstein has published recently on developmental education in Pedagogy: Critical Approaches to Teaching Literature, Language, Composition, and Culture; Research and Teaching in Developmental Education (with Pete Johnson); and the Chronicle of Higher Education. She teaches at the University of Cincinnati in the Center for Access and Transition. 
stance, however, I document Noah's own metamorphosis as he moved from public high school experiences to college basic writing.

First, though, I present critical background for viewing the roots of the current situation in Texas public education. While at first glance this background may seem local in nature, it is helpful to remember that policies first introduced in Texas are now part of the 2002 federal No Child Left Behind Act. The shape shifting demanded of my students locally in Texas as they make the transition from standards-based education to college basic writing will be required of many of our students now that standards have become a national mandate (Zancanella and Noll).

\section{Don't Mess with Texas}

The voices of the status quo will say, let's continue to ignore the problem. I say, let's fix it.

--Texas Governor George W. Bush, 1998 Speech to Texas Education Agency

(cited in Valencia, Villarea, and Salinas 290)

In 1998 Texas Governor George W. Bush proposed that a single statestandardized reading test be used to determine promotion from third grade to fourth grade for Texas public school children. This proposal became law in 1999, and four years later, in 2003, the first cohort of third graders took a new high stakes reading test, the TAKS, Texas Assessment of Knowledge and Skills to determine their eligibility for promotion to the fourth grade (Valencia, Villareal, and Salinas 290-91). TAKS superceded the previous accountability test, the TAAS, Texas Assessment of Academic Skills. The Texas Education Agency explains the differences between the two tests as follows: "TAKS covers more subject areas and more grades than did the TAAS" (Texas Education Agency).

The year 2003 is also notable in recent Texas history because the state legislature voted to pass a new congressional, mid-decade redistricting plan proposed by Republicans, just a few years after the 2000 census-based congressional district map was drawn. Although Texas will soon become a majority minority state, that is to say, a state where the majority of citizens are members of minority groups, the revised redistricting plan creates districts that clearly favor white Anglo voters by carving out districts often several hundred miles long that include majorities of white voters in areas in which state legislators once served chiefly people of color (Bernstein, "Hammer"). 
In the spring of 2003, Democratic state representatives tried to block the plan by leaving for Oklahoma during the $78^{\text {th }}$ legislative session, thus breaking the state-mandated quorum for voting on the plan. In the summer, when the plan was brought up for vote to the state senate during a special legislative session called by Governor Rick Perry, eleven Texas state senate Democrats left once again, this time for New Mexico. Nonetheless, one of the senators broke with his colleagues and returned to Texas. The redistricting plan passed and became state law, though it continues to be challenged not only by Democrats, but also by people of color, poor communities, and progressive advocates (Bernstein "Hammer").

The state legislature passed other bills in the 2003 session that, collectively, seemed to respond to Anglo worries about the impending loss of Anglo majority status. For example, a new law passed that requires all Texas public school children, regardless of citizenship status, to begin their school day by reciting not only the pledge of allegiance to the American flag, but also a pledge to the Texas state flag: "Honor the Texas flag; I pledge allegiance to thee, Texas, one and indivisible" (Gillespie "Flag Pledge" ).

Not incidentally, the legislature decided that college tuition would no longer be regulated by the state-meaning that individual public universities could raise tuition as high as they so desired (Coleman). But perhaps most relevant for this study, the legislature mandated that, beginning in 2005 , "college readiness" would be determined for public school students as early as the eleventh grade by yet another level of the Texas Assessment of Knowledge and Skills high stakes testing (Sunset Advisory Commission). If Texas public school children, residents, or citizens, are "one and indivisible" in any regard, it is in their continual experiences with high stakes testing, a program that one Texas public school teacher of my acquaintance calls "No Child Left Untested."

Valencia, Villareal, and Salinas, citing data on the results of the Texas state-mandated assessments, emphasized that the "data on race/ethnicity have demonstrated a pervasive and unwavering pattern: Mexican American and African American students_compared to their White peers-have significantly higher rates of failing the TAAS [which preceded TAKS] exitlevel test" (288).

As Raul Ybarra suggests in his study of cultural dissonance for Latino students in basic writing courses, “...we need to find other means of helping students overcome their feeling of disaffiliation with school" (49). In Texas, as elsewhere, the disaffiliation of Latino students with school is culturally 
embedded, written into state law, and exacerbated by the circumstances of distressed, inadequately funded, under-resourced public schools. When Bush moved from the Texas state house to the White House in January of 2001, he brought his educational mandates with him, appointing Houston Independent School District superintendent of schools Rod Paige as education secretary. Shortly thereafter, a coalition of Republicans and Democrats passed the "No Child Left Behind Act" into federal law. The cycle of statemandated tests faced by Texas public school children thus became required for all children enrolled in US public schools (Metcalf).

\section{Taking Texas to TAKS}

In Texas, the public school curriculum is focused on fulfilling statemandated test objectives. The third grade CLEAR English Language Arts Curriculum for the Houston Independent School District, anticipating the first TAKS writing test in the fourth grade, offers the following advice:

Students should be able to select an appropriate form and organization strategy to write a composition in response to a prompt. The composition must maintain focus. In order to select an appropriate form, students need to have experience with a variety of forms of writing (A7).

Although this directive is presented for third graders in anticipation of their fourth grade year, these goals foreshadow objective 4 of the eleventh grade TAKS writing test, using the language of writing process pedagogy.

Objective 4 states, "The students will, within a given context, produce an effective composition for a specific purpose." While this objective requires students to "write in a voice and style appropriate to audience and purpose" and "organize ideas in writing to ensure coherence, logical progression, and support for ideas," directives for mechanics and proofreading are highlighted in subsequent sections of Objective 4:

Writing/writing processes...proofread writing for appropriateness organization, content, style, and conventions. Writing/ evaluation...evaluate writing for both mechanics and content.

(Texas Education Agency, 11 Exit Level English Language Arts, 32) 
Objectives 5 and 6 also emphasize mechanical correctness, as opposed to organization and content. Objective 5 requires the student to concentrate on writing "as correctly and clearly as possible.... This means that when a student writes a composition, he or she is able to follow the rules of correct spelling, capitalization, punctuation, grammar usage, and sentence structure." Objective 6, "Revision and Editing, assesses the student's ability to both improve and correct passages created to resemble student writing" (Released Tests).

In examining the tests more closely, one notices immediately that "editing" in this case means local, sentence-level editing. On the $4^{\text {th }}, 7^{\text {th }}$, and $11^{\text {th }}$ grade tests for 2003, no questions are asked about the possibilities of moving or eliminating or clarifying paragraphs or paragraph structure. Students are not allowed to offer their own suggestions for improvement, but instead must select the "correct" response from a multiple-choice list.

While the emphasis of the tests seems to focus on a process-based approach to writing, "correctness" in standard written American English is emphasized over and over again (Released Tests). Correctness is clearly a desired goal for success in student writing (Delpit). Nonetheless, assessing a student's writing ability based on one writing sample produced in a highstakes testing situation is more problematic, especially for English Language Learners (Valencia, Villareal, and Salinas; Leki; Blanton). Moreover, funds for public schools depend on students' performance on the TAKS, a mandate that is echoed in the NCLB legislation. Both in Texas and nationally, distressed public schools are denied funds when students score poorly on standardized tests. This portion of the mandate presents high stakes indeed for all concerned parties (Katz; Bernstein "Test Case"; Guerrero; La CellePeterson).

In Houston alone, Latino children constitute $58.1 \%$ of the publicschool-aged population (Houston Independent School District). Although not all of these students would be categorized as English Language Learners, $55.8 \%$ of the students enrolled in the Houston Independent School District fall into the following categories (although home language is not listed): 28.9\% Limited English Proficiency, ESL 8.3\%, or 18.6\% bilingual (Houston Independent School District).

\section{Gone South: Teaching Basic Writing in Houston, Texas}

In the fall of 2003, I began my third year of teaching basic writing at 
an urban open-admissions public university in Houston. As a white Anglo Jewish northerner who had taught writing in public and private universities and colleges in Pennsylvania and Ohio since 1986, I was still quite new to the South. I was fortunate, however, in fall of 2003, to be involved with a federal Title V grant specially designed to "close the achievement gap" for Latino college students in Texas. Because of the experimental teaching encouraged by the grant writers, I was able to create and teach a linked course in basic writing and reading skills. All but two of the students in the course identified as Latino, and many of the students would be identified as English language learners or generation 1.5 students. The latter group of students is tentatively defined by Harklau, Siegal, and Losey (citing Rumbaut and Ima) as "immigrants who arrive in the United States as school age children or adolescents and share characteristics of both first and second generation" (4).

Many of the students in this class, although they had lived in the US for much of their lives, were considered residents of Texas, but were not naturalized US citizens. As legal US residents living in Houston, these students, like US citizens, paid $8.25 \%$ sales tax, but they attended under-funded public schools and, unlike US citizens, they were not able to vote. In addition, some students may have been undocumented, an "illegal" status characterized by instability since discovery by the US Citizenship and Immigration Services (a bureau of the Department of Homeland Security which absorbed what was formerly the INS) could lead to deportation (Farris).

In any case, my students, like many graduates of Texas public schools, found that their education had focused on preparing them for passing statemandated standardized tests. However, their schooling had not prepared them for the intellectual inquiry demanded in college reading and writing courses (Hillocks; McNeil; McNeil and Valenzuela; Blalock and Haswell; Bernstein "Test Case").

Since this fall 2003 basic writing course was linked to a course in reading skills, the writing assignments were focused primarily on course readings. This approach was clearly new for the students, since reading and writing were generally considered separate areas of study in their previous workand since their preparation for TAAS (which preceded TAKS) did not generally prepare them to read, analyze, or write critically about longer, more sustained texts.

After working through the course readings by means of writing and discussion, most of the students found themselves returning again and again 
to the systemic problems of K-12 education. They found that other themes suggested by the course readings (and of initial interest for course focus), such as racism and discrimination, were embedded in the readings on education. While initially, several students resisted the theme of "education" as a topic for study and investigation, as well as a matter for self-reflection, these students related that previous teachers had asked them to think about education mostly in terms of individual experiences, not in terms of systemic issues.

In fact, most students had not previously read or discussed the idea of education as a systemic process - and had not explored the social construction of their own subject positions within that system. Despite all of the clear social inequities faced by the students in my fall 2003 basic writing course, there also was evidence of strong motivation and resilience. Students learned how to set high goals for themselves for intellectual achievement and remained engaged in helping to plan the work of the course.

The reading and writing in this course focused largely on literacy and education, moving back and forth between historically contextualized narratives (Narrative of the Life of Frederick Douglass; Incidents in the Life of a Slave Girl by Harriet Jacobs; "Graduation" by Maya Angelou) and contemporary analyses (an excerpt from Jonathan Kozol's Savage Inequalities; Jean Anyon's study "Social Class and the Hidden Curriculum of Work"; a series of New York Times articles on dropout rates in the Houston Independent School District). ${ }^{1}$

The New York Times articles seemed particularly compelling for these students. The articles documented how an audit of Houston public middle and high schools, some of which were mentioned by name and were schools that the students had attended, not only lied about dropout rates and college matriculation numbers, but also encouraged attrition for students who were likely to score low on standardized tests (Schemo "Questions"; Schemo "For Houston Schools"). What students previously had intuited about their own situations and those of their peers had been documented in a national newspaper:

Now, some [in Houston] are questioning whether the [Texas] miracle may have been smoke and mirrors, at least on the high school level. And they are suggesting that perhaps Houston is a model of how the focus on school accountability can sometimes go wrong, driving administrators to alter data or push students 
likely to mar a school's profile-through poor attendance or low test scores-out the back door. (Schemo "Questions")

In response to these findings and to their own reflections and class discussions, students wrote narratives and analyses themselves, reflecting on their readings and past experiences in order to contemplate the future. For their last essay in the course, students collaborated on a list of topics that would be appropriate for a culminating assignment in the course. This list included such items as:

- What does education have to do with survival? Why do you think so? Why does reading Anyon's article (and perhaps the work of Douglass, Jacobs, Kozol, Angelou, and/or the New York Times ar ticles) help to strengthen your understanding and analysis of this issue? Who would benefit from reading your analysis of this issue? Why?

- Were Anyon's classifications of social class and schooling ever dis cussed in your previous education? Why or why not? What are the results of these classifications on your own schooling? Why do you think so? What changes need to be made? Why? Why does a reading of Anyon's article help to deepen your understanding of these questions? Who would benefit from reading your analysis of these questions? Why?

Students responded to their own calls for action by citing personal histories and course readings, and by advocating for change (all names in the following excerpts have been changed).

Gabrielle, who left Mexico to attend high school in the United States, wrote about her first day of high school in Houston:

As soon as I arrived to the school I expected some one to help me translate or to introduce me to teachers. But instead a student walked me to every single class to show me how to get there and at what times. I felt so lost and confuse because of the immensity of the school. The firs three periods of classes made me feel so ignorant and stupid, no other words I could speak more than "I don't speak English." Very few people helped me to translate what the 
teacher said. I remember how his cold words stroked my ears with force, and his refined dialect perplexed my mind with a revolution of questions. Regardless of the shocking day I passed I did not give up. I saw my self- trapped with no escape, but I also visualized that everything had a merit an effort and a recompense.

Martin was intrigued by Anyon's suggestion that schools segregated by social class "contribute to the development of certain potential relationships to physical and symbolic capital, to authority, and to the process of work" (188-89). To better understand this concept, he wrote:

The thing that I get from this quote is that history can repeat itself. The one thing that I can think of is my family repeating history over and over. Well, my family on my dad's side repeat history all the time. The males from the $\mathrm{S}$ side never graduated from high school. When I found that out I needed to change history myself. I want to start a good and new history for my family. I am proud to say that I was the first $\mathrm{S}$ male to graduate from high school. So know the young S males have some one to look up to, to finish high school.

Caroline was moved by her reading of slave narratives and immediately understood the relevance of these readings for herself and her peers. Contextualizing the issues with which she and her classmates struggled regarding the inhumane conditions faced by previous generations, Caroline's essay begins: "We come from a legacy of people who when they were told education had novalue or that it meant nothing still made an effort to learn." Her essay continues to document the efforts of Jacobs and Douglass and the importance of their narratives for twenty-first century college students. Caroline concludes:

As much as Harriet and Douglass suffered to provide us with the significance of education we must prove to them that we have learned the true meaning of education. From learning a language not native to our own to making history through a painting, knowledge gets us places that we didn't know existed. Each day is a celebration to honor those that gave us the key to a new life. 
At times, the students' writing conveys a sense of personal struggles and frustrations. Nonetheless, the students noted a developing sense of agency, an ability to view their own stories as part of the larger struggle that they discovered in their readings. They learned that they were not the only ones concerned with systemic change in school structures that would provide an equitable education for all students.

Joan, a white middle-class fourth grade teacher with whom I worked in the Houston public schools, reinforced this sense of agency. As an interested insider, Joan was concerned with how students developed as writers along the continuum of accountability testing required by the state, especially since her fourth grade students were preparing for their first TAKS test in writing. The students appreciated Joan's involvement with their own writing and several of them initiated a correspondence with her in order to better focus their own sense of audience and purpose. In addition, the students were intrigued by how a real audience-and a Houston public school teacher-would respond to their efforts to speak back to the system. Joan did not disappoint them. Addressing the students in a group letter, she wrote:

You have to stop the vicious cycle we have seen in education. Many of you said that the poor schools get poor teachers, poor material, and poor students. It is up to each and every one of you to break the cycle. You have to demand an equal education for your brothers, sisters, nieces, nephews, and your own children.

"Learning is a process that takes time and is never ending because we learn something everyday." "Education should be provided equally and at equal levels for everyone. Learning is learning and it is only fair that everyone receive a fair education in an inner-city school as well as a suburban school." "Education is the key to success." "Education is about survival and the skills needed to survive are taught through past mistakes and learned from experience. Education helps people to survive in our ever changing world." "The most important thing in life is education and without an education, you are worthless." These are your words, not mine. Walk the walk. Make a difference. The future of education depends on it.

Joan stressed self-advocacy and community activism throughout her letter, using the students' own writing to emphasize the significance of the challenges that they had already set for themselves. 


\section{Learning: The Story of Noah}

In order to investigate my perceptions of this course in more detail, I followed the progress of another student from the fall semester class, Noah, who struggled all semester with reading and writing. Although Noah would need to repeat the writing portion of the course with me in the spring semester, his goals remained constant and clear. As our case study developed, I shared research and drafts of this article with Noah. In particular, I emphasized the question that grounded my inquiry: how might students make sense of their own subject positions as English language learners within an urban public school system that emphasized state-mandated accountability testing?

As seen through the lens of practitioner-inquiry research, Noah's story was particularly interesting to me because it provided an opportunity to investigate "how teachers and students co-construct teaching and learning across classrooms and across contexts" (Cochran-Smith and Lytle 44). As Cochran-Smith and Lytle suggest, "When teachers redefine their own relationships to knowledge about teaching and learning, they often begin to reconstruct their classrooms and to offer different invitations to their students to learn and to know" (52).

Noah was a first-year college student of traditional age whose first language was Spanish; he moved to the United States from a small town in Mexico at the age of nine, just before fourth grade. Like the other students in the fall semester, Noah was part of the first generation in his family who had an opportunity to attend college, and he contemplated becoming a teacher himself. Having graduated from high school in the top ten percent of his class, however, Noah now felt frustrated by his lack of adequate preparation for college. At the same time, as he read and thought about the assignments, he began to recognize his own experiences in the context of the course readings.

Because Noah's US schooling took place in Texas urban public schools, his situation seemed even more complicated than that of the typical English language learner. Valencia, Villareal, and Salinas cite considerable research to discuss how education for English language acquisition is delivered to Texas public school students who are identified as English language learners (ELL). Initially, these researchers suggest, most children are assigned to "transitional bilingual education (TBE)": 
In Texas, for example, ELL children in bilingual programs are classified as "English-proficient" when they demonstrate oral fluency by obtaining a score at the $40^{\text {th }}$ percentile or higher on a standardized English language assessment measure. (Texas Education Code, 1999, 275)

Nonetheless, "TBE programs last only about two to three years," Valencia, Villareal, and Salinas recount, noting that exit criteria for such programs are based on oral proficiency, rather than proficiency in academic English. Using oral proficiency alone as the sole measure of English language acquisition tends, not unexpectedly, to have a negative impact on students' development of reading and writing skills, which will be required not only for future tests but also-and even more critically—-for success in further education.

After encountering this research as part of our case study, Noah noted in our discussions that the conditions of schooling described by Valencia, Villareal, and Salinas clearly illustrated his own circumstances. As Noah related, he was not punished for or forbidden from speaking Spanish in school, as previous generations of US-educated Latino children had been (Anzaldúa, Valencia). However, as a student who did not yet speak English, Noah found that there were other difficult consequences for entering a school system focused on accountability testing.

Similar to the circumstances that Gabrielle recounted in her essay, Noah received no assistance in dealing with language issues as he began fourth grade (Valdés). Although the school told Noah that he would be enrolled in a program to learn English, this program never materialized. In fourth grade, Noah's language arts classes were taught in Spanish, while the teacher would speak in English to the other teachers in the school, if not to her students. Fourth grade math was conducted entirely in English, which Noah did not yet understand. As a result, he found it difficult to pay attention and often fell asleep in class.

In fifth grade, an Anglo teacher who spoke only in English to the students (but in Spanish to their parents) taught Texas history using only books written in English, which many of the students still had difficulty understanding. The Spanish translation of the Texas history textbook remained off limits to students. By sixth grade, Noah reported that, since he did not speak much English, his teacher initially tried to help him. However, his teacher's assistance was not consistent and Noah was often sent down to 
the lower grades to help take care of the younger students. At the time, Noah stated, he was happy about this situation, but "it wasn't good overall because if I'd stayed [in the sixth grade] I would have learned more English." In addition, because Noah's neighborhood in Houston had a high crime rate, his parents were afraid to allow him to play outside, which Noah understood as yet another lost opportunity to learn English.

At this juncture, Noah's story seems to follow the pattern described in Kozol's Savage Inequalities, rife with the lost opportunities and the silences endured by students who do not conform to state-mandated standards, students that Schemo describes as "push[ed] out the back door." However, in high school, Noah made a remarkable discovery. He described himself as "a student who likes to try different things," who, perhaps because of the challenges he faced in learning English, understood that he needed to be "alert and pay attention to what's going on." He was especially fascinated by "how things worked" and this interest led him to try his hand at skills such as carpentry, electronics, and art. An art teacher at Noah's high school eventually hired Noah to help renovate an old shed into an art studio in the art teacher's backyard, thus drawing together many of Noah's interests.

Noah's art teacher soon became his mentor. Since advanced classes were closed to students who were not identified as meeting high English proficiency standards, Noah enrolled in art classes. Noah found that "art helped to relieve stress and express emotions." Art was also a means of learning English for Noah, as his mentor continually emphasized. Because becoming an artist meant creating a portfolio, Noah's mentor suggested that "art is writing as well as painting."

By the fall of 2003, when he first enrolled at the university, Noah understood that "if I didn't go to college, I wouldn't have the opportunity to express my feelings and nothing would change about my life." In that first semester, he felt often that college was too hard for him and that he "didn't know how college worked." In addition, Noah was depressed by the difficulties that he continued to have with English. However, by the spring semester of 2004, Noah related that he knew that he would need to "be strong and keep fighting for my education-keep working, keep fighting, keep going."

Noah expressed relief that he was not alone in his struggles to learn English in Texas public schools. Nonetheless, Noah also noted his disappointment that the problem continues to be so widespread. Perhaps such discussions might seem dispiriting for students caught up in the mechanisms of inequitable public schooling in Texas, and yet when these issues 
were exposed as systemic problems rather than individualized notions of "success" or "failure," Noah's investment in his own education grew that much stronger.

Noah enrolled in a second semester of basic writing, this time linked with an introductory American Studies course that offered a cultural studies perspective. This six-hour course was designed for students who need to repeat the basic writing course, usually for reasons of English language acquisition and proficiency. In this second course, he discovered the work of Howard Zinn who, in A People's History of the United States, defamiliarizes the study of United States history by presenting a more inclusive point of view. Noah used this opportunity to continue to fill in the gaps in an education that had focused more on readiness for standardized testing rather than on preparation for college study.

In the brief samples that follow, I include writing from two of Noah's essays, one from each of the two semesters in which he has been my student. In a late semester essay for the fall 2003 linked reading and basic writing course, Noah wrote about the implications of Jean Anyon's study "Social Class and the Hidden Curriculum of Work" for his own schooling. In his essay written at midterm for the spring semester linked American studies and basic writing course, Noah focused on Howard Zinn's presentation of the history of Christopher Columbus' voyages to the Caribbean. Noah's essay contrasted Zinn's version of Columbus' voyages with more traditional versions as presented in high school (and earlier) and in reading prompts for state-mandated standardized tests. Following are excerpts from those essays:

\section{November 2003}

In my high school I think that we didn't have some of the resources because we use to borrow the cafeteria and library from a middle school next to my high school. We used to cross a bridge every day to eat. When it was time to do big projects we would cross the street to go at the library or if you were looking for a book for your reading classes, even though we use the cafeteria to do our test (TAAS). It was very cold inside and students were complained. In my English class I saw that boxes in my classroom arrived, but they stayed for two weeks without being opened, but when the teacher finally opened them we saw that they were books. I remember we didn't use them all the school season. When I read 
this quote from Anyon's article “available textbooks are not always used" (Anyon 177). It attracted me because it brought memories from my high school. The teachers only ordered books just to have nice bookshelf, instead of giving them to the students so that they could learn. I think that Anyons tries to say that teachers' work based on what they think they know, but I believe that a classroom should be book based. Such that the students work to what the book say. What Anyon says about a Working-Class Schools, is true...

\section{March 2004}

Public schools give us the TAAS test, which seems to include material that I think is not beneficial for College. In the reading section of the TAAS tests there were stories about Christopher Columbus. One of the stories was not making sense by knowing the real story as when I read "Columbus, the Indians, and Human Progress" Columbus said "they would make fine servants" (Zinn 3). This is a quote where students are not going to find on these readings on the TAAS Test, so I think if we give them a well-rounded acknowledgement of Columbus would benefit students more. They would be better prepared in their education. That would be given the ability to interpret Columbus in their own way...

I do not know why public schools hide many things as history like Christopher Columbus, but working as a teacher I would do every thing to help students to get a better understanding on history and know more about history. When is time to be on the next level (college), students can be prepare to do a big step and move forward without difficulties.

What stands out for me in these samples of Noah's writing is his growing awareness of how his reading and writing were shaped by standardized testing. In his fall semester essay, Noah identifies how the problems of education for test preparation interfered with his schooling, especially in terms of reading. As Noah continued to think through this interference, he considered how students were not given full or accurate information about history. Since the state accountability tests focus on short reading passages, there is neither time nor space enough to allow for multiple perspectives. As Noah suggests, this truncated version of the Columbus story is presented to students as "history." 
In his conversations with me in the spring semester, Noah speculated that one of the reasons that students described their schoolwork as "boring" might be "because their reading level in English was low." He noted that as a result of a more concentrated focus in reading and critical thinking, his interest and comprehension in reading in English had improved considerably since beginning college.

As a result of his own evolving processes, in the second semester, Noah's writing focused on the problematic nature of the reading section of the state-mandated test. The readings for the test were generally short and did not allow for interrogation or discussion. Test preparation followed the same pattern, with much focus on systematically responding to questions and how to identify correct answers. Critical analysis of the reading was rarely, if ever, a subject of classroom inquiry.

Noah perceived the problem as one of instructional focus. He had discovered in his first year of college that his professors placed more value on critical thinking, analytic reading, and persuasive writing than on "finding the right answer." In that regard, he suggested that students needed solid preparation for college that focused on more intellectual aims, rather than on preparation for testing. Rather than conclude in despair, Noah grounded his reflections in advocacy for future generations of students in his community. As Noah challenged himself to make sense of his reading in order to fashion his thoughts into writing, he also considered the necessity of changing the content of schooling in order to achieve a more felicitous outcome.

\section{Closing Concerns}

Goodman suggests (and Noah concurred) that:

development [of quantitatively measured standard usage conventions] does not follow a straight line from one writing episode to the next.... Development reflects the growing experience of the writers and their personal histories within a specific cultural context as they begin to control written language to express their meaning.... (Vygotsky 1986, 200)

This articulation of the development of the writing process illustrates yet another concern expressed by Noah and his peers. The written product of a single standardized test might not necessarily reflect the most accurate 
Bernstein, Jake. "The Hammer Drops: Democrats Define the Case Against the Republicans Redistricting Map. The Texas Observer. 18 July 2003. $<$ http://www.texasobserver.org/showArticle.asp? ArticleID $=1402>$.

__- "Test Case."The Texas Observer. 30 August 2002.<http:// www.texasobserver.org/showArticle.asp?ArticleFileName $=020830$ f1.htm>.

Blalock, Glenn, and Richard Haswell. "Student Views of TAAS." February 2003. 〈http://comppile.tamucc.edu/TAAS/index.html〉.

Blanton, Linda Lomon. "Classroom Instruction and Language Minority Students: On Teaching to 'Smarter' Readers and Writers.” In Harklau, Losey, and Siegal, 119-142.

CLEAR English Language Arts Curriculum. English Language Arts Grade 3: Model Lessons, Unit 6, Fantasy (Training Document). Houston Independent School District, November, 2003.

Cochran-Smith, Marilyn, and Susan Lytle. Inside/Outside: Teacher Research and Knowledge. New York/London: Teachers College Press, 1993.

Coleman, Garnet F. Texas State Representative, District 147. Personal Communication. 6 February 2004.

Comfort, Carol, Ed. Breaking Boundaries. Upper Saddle River, NJ: Prentice Hall, 2000.

Delpit, Lisa D. Other People's Children: Cultural Conflict in the Classroom. New York: New Press, 1995.

Farris, Sara. "Your Textbook Is in the Library: Go Find It." Fifty-Fifth Annual Convention of the Conference on College Composition and Communication. San Antonio, Texas. March 2004.

Flag Pledge. Texas State Library. 18 April 2004. <http://www.tsl.state.tx.us/ ref/abouttx/flagpledge.html>.

Gillespie, Spike. "Reading, Writing, and Pledging." The Texas Observer 24 October 2003: 30-31.

Goodman, Yetta. "The Writing Process." Notes from a Kidwatcher: Selected Writings of Yetta Goodman. Ed. Sandra Wilde. Portsmouth, NH: Heinemann, 1996. 191-206.

Guerrero, Michael D. "Research in Bilingual Education: Moving Beyond the Effectiveness Debate." In Valencia (Ed.), 170-191.

Harclau, Linda, Kay M. Losey, and Meryl Siegal, Eds. Generation 1.5 Meets College Composition: Issues in the Teaching of Writing to U.S.-Educated Learners of ESL. Mahwah, NJ: Erlbaum, 1999. 
_. "Linguistically Diverse College Students: What Is Equitable and Appropriate?" In Harklau, Losey, and Siegal, 1-14.

Hillocks, George. The Testing Trap: How State Assessments Control Learning. New York/London: Teachers College Press, 2002.

Houston Independent School District. Facts and Figures. January 2004. <http://www.houstonisd.org/vgn/images/portal/cit 7634/ 22560382004FactFigures.pdf $>$.

Katz, Susan Roberta. "Does NCLB Leave the U.S. Behind in Bilingual Teacher Education?" English Education 36.2 (January 2004): 141-52.

Kozol, Jonathan. Savage Inequalities: Children in America's Schools. New York: HarperCollins, 1992.

Language Arts $11^{\text {th }}$ Grade. 23 May 2004. $<$ http://www.roundrockisd.org/academics/alignedcurriculum/2003-04/Langarts/Secondary/ 11thgrade.doc $>$.

LaCelle-Peterson, Mark. "Choosing Not to Know: How Assessment Policies and Practices Obscure the Education of Language Minority Students." Assessment: Social Practice and Social Product. Ed. Ann Filer. London/New York: Routledge, 2000. 27-42.

McNeil, Linda M. Contradictions of School Reform: Educational Costs of Standardized Testing. New York: Routledge, 2000.

, and Angela Valenzuela, "The Harmful Impact of the TAAS System of Testing in Texas: Beneath the Accountability Rhetoric." In Raising Standards or Raising Barriers? Inequality and High Stakes Testing in Public Education, edited by Gary Orfield and Mindy Kornhaber. 2001. <http:// caracas.soehd.csufresno.edu/whatsnew/valenzuela/ Valenzuela1\%20.pdf $>$.

Metcalf, Stephen. "Reading Between the Lines." Nation. 10 January 2002. $<$ http://www.thenation.comdoc.mhtml? $\mathrm{i}=20020128 \& \mathrm{~s}=$ metcalf\&c $=>$.

Meyer, Richard. "Shifting to Political Action in Literacy Research and Teacher Education." English Education 36.2 (January 2004): 134-40.

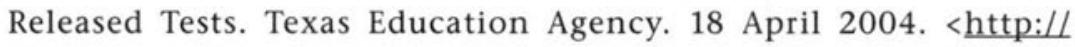
www.tea.state.tx.us/student.assessment/resources/release/ \#2003>.

Schemo, Diana Jean. "For Houston Schools, College Claims Exceed Reality." New YorkTimes. 28 August 2003. <http://www.nytimes.com>.

_. "Questions on Data Cloud Luster of Houston School." New York Times. 11 July 2003. <http://www.nytimes.com>.

Shor, Ira. Empowering Education: Critical Teaching for Social Change. Chicago/ 
London: University of Chicago P, 1992.

Siegel, Marjorie, and Susana Laura Fernandez. "Critical Approaches." Methods of Literacy Research: The Methodology Chapters from The Handbook of Reading Research . Vol. 3. Ed. Michael L. Kamil, Peter B. Mosenthal, P. David Pearson, and Rebecca Barr. Mahwah, NJ: Erlbaum, 2002. 65-75.

Steele, Claude M. "Not Just a Test." Nation. 15 April 2004. <http:// www.thenation.com/doc.mhtml?i=20040503\&c=1\&s=steele $>$.

Sternglass, Marilyn. Time to Know Them: A Longitudinal Study of Writing and Learning at the College Level. Mahwah, NJ: Erlbaum, 1997.

Texas Education Agency. Press Release. 30 May 2003. <http://www. tea. state.tx.us/press/takscores03.html>.

Texas Education Agency. Student Assessment Division. TAKS: Texas Assessment of Knowledge and Skills, Information Booklet 11 Exit Level English Language Arts. 2002. <http://www.tea.state.tx.us/studentassessment/taks/ booklets/>.

Texas Higher Education Coordinating Board. "Success Initiative." Summary of Sunset Legislation: $78^{\text {th }}$ Legislative Session. July 2003. $\leq$ www.thecb.state. tx.us/cfbin/ArchBottom.cfm?.DocID $=620 \&$ Format=Word $>$.

Valdés, Guadalupe. Learning and Not Learning English: Latino Students in American Schools. New York: Teachers College Press, 2001.

Valencia, Richard R., Ed. Chicano School Failure and Success: Past, Present, and Future. $2^{\text {nd }}$ ed. London/New York: Routledge, 2002.

_. "The Plight of Chicano Students: An Overview of Schooling Conditions and Outcomes." In Valencia, Ed., 3-51.

_ Bruno J. Villareal, and Moises F. Salinas. "Educational Testing and Chicano Students: Issues, Consequences, and Prospects for Reform." In Valencia, Ed., 253-309.

Ybarra, Raul. "Cultural Dissonance in Basic Writing Courses." Journal of Basic Writing 20.1 (2001): 37-52.

Zancanella, Don, and Elizabeth Noll. "Teaching Education in Language Arts and Literacy in the Era of 'No Child Left Behind.'” English Education 36.2 (January 2004): 101-103.

Zinn, Howard. A People's History of the United States. Abridged Teaching Edition Revised and Updated. New York/London: The New Press, 2003. 


\title{
Study of Teacher Error: Misreading Resistance in the Basic Writing Classroom
}

\author{
Sara Biggs Chaney
}

\begin{abstract}
Many scholars have argued for the important role of student resistance in building critical literacy. One common mode of addressing student resistance in the writing classroom, academic re-positioning, focuses on putting the resistant student in dialogue with the culture of critique traditionally valued by the university. This article explores one teacher's experience of the limits of this approach. After working with a student whose final act of plagiarism caused the author to rethink her assiumptions about academic acculturation, she reconsiders the practical' "meaning" of stulent resistance for both student and tecicher. She concludes by arguing for the importance of more nuthentic power sharing in the basic writing classroom.
\end{abstract}

Much work on the issue of student resistance in the composition classroom has raised the suggestion that resistance, effectively addressed, is a crucial catalyst for the emergence of greater critical literacy among students. John Trimbur sums up the many uses of the term "resistance" in critical scholarship as "the divergent ways individuals and groups seize a degree of relative autonomy within the institutions of schooling, articulating identities and purposes that in one way or another withhold consent from the dominant enterprise and its hegemonic claims" (7). Theorists of emancipatory literacy have seen much promise in this withholding of consent on the part of the student because of its double-edged ability to both hinder student learning and to expand it beyond what the teacher or student originally thought possible. In this spirit it has seemed only logical to me, as an instructor interested in basic writing, to make my students' common forms of resistance-their skepticism, and partial or complete alienation from schooling practices-the unlikely gateway to their future suc-

Sara Biggs Chaney is a Ph.D. candidate at Indiana University in Bloomington, where she is working on a dissertation dealing with the use of public writing pedagogy and service learning in basic composition. Beginning in the fall of 2004 she will be one of four assistant directers of first-year writing at IU-Bloomington. 
cess in higher education. The most suspicious and resistant students in any one of my classes of fifteen, I have thought, do not need to change their resistant attitude about the academy and the authority it represents, so much as to reposition themselves in a way designed to make their resistance a road to empowerment and possible cultural change. I have often presumed that in that very repositioning, my students' often critical attitude toward schooling, and particularly writing, will somehow (as in some academic Cinderella story) transform itself into a statement of carefully qualified critique exemplary of all that the academy values. This article is about the troubling results of one such effort of repositioning. This particular experience has taught me to reconsider how a common attempt to teach academic critique may effectively silence students at the very level on which they most want to be heard.

Late one October afternoon my basic writing class was sharing topics for their upcoming evaluation paper, a standard assignment culled straight from their textbook, Axelrod and Cooper's Reading Critically, Writing Well. Although nearly every student in the class chose to evaluate a movie or book, one student, whom I'll call Amber, planned to take her own path. Sitting right next to me, and looking in a neutral fashion into my eyes, she said: "I want to write an evaluation of paper writing, and how it's really pointless and doesn't teach you anything."

I smiled (or then again maybe I just bared my teeth, as one does when on the offensive), and tried to answer with enthusiasm. I told her I was really glad she was taking her own approach to the assignment, and gave her some suggestions about the most scholarly, analytical way to approach such an assignment. She received them silently; we moved on to the next topic on our agenda, and for the moment the topic slept.

But as promised, the first draft of Amber's paper was a fairly organized, deliberate and reasonably academic attack on the use of paper writing as a common method of evaluation in college coursework. She pressed two major points in her paper:

1) That papers are an inadequate way of assessing student learning. Students may not be able to write abstractly about their learning, but that doesn't mean they can not put their learning into practice in practical situations.

2) That students should be able to benefit from course activities that are more closely related to their field of study. "Is it better for a dentistry student to practice filling teeth, or to write a paper about it? We don't pay 
our dentist for writing."

Amber went on to argue that only English and Journalism majors use writing skills in their careers, and only they should have major required writing courses. Taking direct aim at some of my more practical, skill-centered writing lessons, she wrote: "Will a nursing student need to know the value of a good transitional sentence? I don't think so." If I had been in doubt before, such examples confirmed for me that Amber had my class (and the institution of the college writing requirement in general) in mind when she lambasted the relevance of writing instruction.

While the enthusiasm for Amber's mini-rebellion was something I had to muster with some effort in the moment, it was not insincere. I was glad, thrilled even, to hear one student take an oppositional stance to academic conventions in her writing because I tended to assume that this kind of stance is the key (or one of them) to a basic writer's successful transition to the questioning of ideas, which is highly valued in college. It was perhaps first and most powerfully noted in Facts, Artifacts, Counterfacts that an effective basic writing curriculum should enable "successful readers and writers [to] actively seek out the margins and aggressively poise themselves in a hesitant and tenuous relationship to the language and methods of the university" (Bartholomae and Petrosky 305). Significantly, this by now well-known approach to basic writing pedagogy presumes that students will first necessarily move to the "center" of academic authority, before making the voluntary journey back out to the margins. By passing first into the "inside," they will "learn how to speak with other forms of authority (to speak with intellectual rather than moral authority), including that form of critical authority that establishes itself by calling attention to and pushing against the voices and structures that enable a writer to write" (Bartholomae and Petrosky 299). And in so doing, they will presumably be newly in control of and able to garner power from an aptitude for institutional critique (or, a predisposition to resistance) that may well have always already been part of their daily lives. This fundamental understanding of what a "good" college writer must eventually be able to do, and thus what a "bad" college writer most urgently needs, has shaped much subsequent thinking about what should go on in the basic writing classroom. It certainly has influenced my own hopes for what might go on in mine.

Perpetuating the emphasis on academically situated critique, or the “critical gesture," Jane Hindman, in her 1993 "Reinventing the University," traces Bartholomae and Petrosky's paradoxical definition of developing aca- 
demic authority in writing - that of the insider's voluntary movement to the margins-primarily in order to point out how the Facts curriculum fails to allow students to achieve it. Hindman argues that the Facts curriculum, while it does emphasize an understanding of academic knowledge construction from the "inside," still inadequately teaches students to reposition themselves in a tenuous and voluntarily marginalized opposition to that same "inside." Although Hindman critiques the Facts curriculum for being perhaps too accommodating and insufficiently critical in its approach to college writing transition, her article still leaves the value of this paradoxical "critical gesture" as central pedagogical goal unquestioned. It remains unquestioned that basic writing students, already likely to be alienated from and critical of academia, should be (only for their own benefit, of course) re-taught their critical disposition in an academically legitimate form. The assumption that we can and should "re-channel" student resistance toward explicitly academic ends appears again in the more recent work of Elizabeth Flynn, who stresses the potentially "productive" nature of reactive resistance when channeled into the right avenues of academic research (32).

When approaching Amber then, basic writer and eager critic of institutional practices, I was happy to imagine that she was well on her way to achieving the critical gesture in her writing, to "setting [herself] against the bias of other critics, other disciplines, other practitioners, even our own conventions" (Hindman 71). After all, my own reading in the composition literature had led me to assume that on this "critical gesture" so very much hangs. Beyond strengthening academic writing, according to Hindman, the mastery of this gesture will ensure students' ability to prove that they have secured "a place for themselves in academic discourse" (57), that "they know how to think" (71), that they can "resist implication" and even "subvert the dysfunctional power structure of a system" (61). To me, all this big talk heavily implied an even bigger pay-off for the critical gesture: That it would make pressured and sometimes disadvantaged new college students into intellectuals (armchair or grassroots, it's not so important here). It would make them successful citizens of the university, if that is what they wanted to be. Maybe that has simply been a way for me to translate my own conviction that basic writing should improve the retention rate of "at-risk" students, and to make it meaningful to this discussion. But nonetheless, I was sure that Amber's resistance could be and should be the beginning of an overall successful acculturation into the academy that would somehow not compromise her already apparent critical ideals. And so I set about trying to 
make good with Amber on the supposed promise that her resistance could hold for her future as a student writer in the university.

On her draft, I decided to present my objection to her argument as a "counter argument" (hence, merely some possible objection floating out in academic space, and not necessarily my own) that she might take into account:

What you say here is very true, and a lot of people in education have a similar argument. But it's also important for you to understand why people in education have thought writing is important, at the very least in order to argue more effectively against it. A lot of people who plan what's taught in schools think that strong reading and writing skills are basic requirements for your further education. So, even if you want to be a dentist, you still need to be a strong writer and reader in order to learn the more difficult things involved with dentistry.

On the other hand, it's important to keep in mind that you are attending a liberal arts college, not a trade school. While at a trade school you might just learn a skill, part of the purpose of a liberal arts education has always been to help you understand and take command of more abstract, general kinds of knowledge-not just how a tooth gets filled, but how we came to live in a culture in which dentistry is available to us. You might be asked to learn more during your four years of college about the history of modern science, or the changes brought to all of our lives by advancing capitalism in the industrial revolution. Writing and reading difficult texts and being able to respond to them will help you get your money's worth out of this kind of education. You are right, it won't all provide you with a manual for tooth-filling, but it will (ideally) help you understand who you are and where you are when you are filling it-and what has made that life possible.

I'd like to see you work to acknowledge these important counter arguments in your paper, and let your claim about paper writing evolve by coming into contact with them. At the very least, you'll get a more serious hearing from those people who are least likely to agree with you-who just so happen to be the same people whose minds you are trying to change! 
My hope was that in using counter argument to qualify her points, Amber would easily find her opposition contextualized in a larger academic conversation. In so doing, she would achieve the Batholomaean paradox of critical acculturation: She would make her own gesture of institutional critique an academically sanctioned one by placing it appropriately in an insider's context. She was already a student predisposed to throw stones at authority from the margins of the university. Perhaps after seeing her marginality as a ticket to the academic club, something that allowed her access to success (as long as she followed a few key rules of academic articulation and acknowledgment), Amber would throw the same stones with a difference.

The final draft of Amber's paper took my counter arguments into account, acknowledging their validity as academic positions and qualifying her own position as a result. Paper writing may not be worthless, she conceded, but it remains overused as a method of evaluation. Her final paper still bristled with resistance to me and to the class, but did so while obediently hedging her own voice with the voices of others. I returned her final to her, with an unqualified "A" and some references to Howard Gardner's work on multiple intelligences, which I thought might interest her. I was certain that her performance on the paper was a successful approximation of the critical gesture (at the very least because it showed a reasonably nuanced understanding of what she was critically gesturing against), and that it therefore improved her chances of success as a college writer and thinker.

Also, and maybe even more importantly, I felt confident that I had been instrumental in Amber's successful transition into the academic writing community. Working with her already very spirited critical posture toward the whole enterprise of writing, I tried to link it to academic debates that address the same concerns in a perhaps slightly more qualified way. My intentions, of course, profoundly influenced how I saw the results in her writing: When she weighed some contradictory evidence and represented both sides of the issue in her argument, I felt sure that she had made a significant (though maybe small) step into an "academic discourse community." Certainly, that was all my classroom could be expected to provide.

Feeling that I had won a minor teaching victory with Amber, I remained very involved with her classroom ideas and how they played out in her writing. I had high expectations for Amber's final paper for my course, a position paper on affirmative action in higher education. As she spoke earnestly to me about it beforehand, I happily suggested ways to refine and complicate her argument. I was confident by now that her somewhat ren- 
egade intensity had found a home in the academy, and I had made it all happen. It wasn't until our last class was finished and I sat with only a pile of papers to remember it by, that I realized Amber had plagiarized well over half of her final argument in favor of affirmative action from an easily recognizable published work on the topic, authored by a well-known public intellectual.

Somewhat incredibly, although she was one of the most adroit writers in my class and by far the best at working with sources, Amber's was the most obvious case of plagiarism that I can recall in my recent years of teaching. The journalistic commentary on affirmative action she had "borrowed" was inserted into the middle of an argument (I assume, hers) which it hardly seemed to relate to, let alone support. She had not even changed any of the words or phrasing (a common student trick to avoid detection). In short, her act was so sloppily executed as to be detectable at a glance. And in retrospect, I realize that had it not been so obvious, I might not have caught it. After all, as I've explained, I had developed a set of assumptions about her as a student that gave me no reason to expect that she would cheat.

Naturally the few minutes spent matching up her paper to the original text on the internet were somewhat bewildering ones, in which several months' worth of emotional investment in teaching quickly unraveled before my eyes. In the context of a semester-long relationship with this student, it goes without saying that I was stung with a sense of betrayal, a feeling that she had reneged on some unspoken promise between us. I was obliged to admit to something hasty and over-simplified in my original assumptions about her progress. I had imagined that the critical pose Amber adopted in her writing toward the educational system I represented could give her purchase on some kind of emerging academic authority. As a result she would achieve, if she wanted it, the academic belonging that writers in her position are often presumed to lack. While her writing showed a good approximation of that critical authority, her plagiarism showed a lack of esteem for it and for the context in which it is valued. By which I mean, though her initial resistance did offer a doorway to improved critical writing, it did not change her more fundamentally negative attitude toward the institution of schooling. And it was exactly this attitude (or resistance) that may have resulted in her willingness to endanger her future in college by performing such a flagrant act of plagiarism.

In claiming that Amber's plagiarism reflected some enduring resistance that my re-positioning tactics failed to address, I realize that I am 
making a leap across all of the many unknowable factors that are always operating in any instance of human behavior. And while it may be true that I can't know for certain why Amber plagiarized, I can be reasonably sure that she understood the consequences of that act within the academic community. The university within which I work, Indiana University at Bloomington, shares with many institutions a significant and growing problem with plagiarism in the first-year writing course. In response to this problem, I and many other instructors have made a continuing effort to connect "anti-plagiarism" instruction more closely to the ongoing work of the course itself. Students began my course learning to paraphrase, summarize, and quote critical sources, and they incorporated those skills into longer assignments that required them to use sources as critical lenses while still adequately distinguishing the source's position from their own. In this curriculum, I hoped that plagiarism would become the opposite of good writing practice as it has been presented to the students. Plagiarism is, in its mildest interpretation, a failure to work with sources effectively — and thus a failure to satisfactorily meet the requirements of the course.

In addition to stressing the importance of source use in critical writing throughout the course, in this particular semester I had at least three fairly time-consuming conversations with my students about the consequences of plagiarism (a zero on the assignment and possibly an $\mathrm{F}$ in the course, as well as a report filed with the dean). Students were given supplementary materials on avoiding plagiarism to refer to when proofreading their own written work. My presentations eventually led to a lengthy troubleshooting session on the topic, in which my students posed multiple examples from their own work- "Is this plagiarism? What about this?"-and challenged me to explain in ever clearer terms the exact nature of the infraction. As a point of comparison, perhaps it is worth noting that most of Amber's classmates moved during the course of the semester to a habit of excessive citation as a way of avoiding possible problems. For most of my students, the possibility of institutional sanctions seemed very real and even frightening, as evidenced by the trend to cover their academic bases as carefully as they could.

It is still possible, although not particularly convincing for me as her teacher, that Amber's plagiarism was a mistake. It may have resulted from her confusion about the rules of citation, or even simple laziness (the end of the semester is, after all, a busy time for any student), and not a re-surfacing of resistance to the material of the course. Of course I cannot know for cer- 
tain. But even if part of Amber's act of plagiarism could be traced back to laziness, or to the common student impulse toward efficiency (maximum outcomes for minimum effort), I am not convinced that makes the act any less appropriately categorized as "resistant." Working within the parameters of John Trimbur's definition of resistance with which I opened this essay - as a variety of acts and expressions of identity that allow the student to "seize a degree of relative autonomy" and" "withhold consent" (7) from the dominant structures of schooling - it is possible to see both lazy avoidance and deliberate rebellion as resistant attitudes. In either case, the student's self-construction and/or lived reality is interfering with the objectives and rules of the course.

As my initial disappointment with Amber started to dissipate, it was replaced with a nagging sense that I was guilty of a misreading. I had imagined that if Amber could stage the critical debates of the academy's "inside" and her oppositional responses to them in a way that satisfied me, she would also be capable of (and interested in) claiming insider status for herself within the academy. While my simple equation of verbal and social initiation is probably in itself very naïve, my assumption that Amber valued this insider status repackaged in the "critical gesture" is even more so. Certainly, her final statement on the value of writing instruction-a blatant act of plagiarism-indicates a lack of regard for the rules and values of the "inside" that changed very little since her first encounter with me in the classroom. Whether motivated by indifference or deliberate treacherousness, Amber was in the end unable or unwilling to perform even the appearance of full consent to the rules. Given that, I have to wonder if my reading of Amber's initial speak-out against the college writing requirement as an opportunity to teach critical positioning in an academic context was more than just ineffective, but fundamentally misguided. Had I misread both the significance of and the appropriate response to Amber's first "stand" against me in the classroom?

I return to Amber's statement-"I want to write an evaluation of paper writing, and how it's really pointless and doesn't teach you anything." Is there a way in which, by focusing only on how I could relate her comment to dominant theories on student resistance, basic writing development, and the transition to higher education, that I failed to hear the cogent critique of academic authority that Amber was already trying to express? Very simply: she does not value academic essay writing, has no internal motivation to excel at it, and is nonetheless compelled to practice it by 
an institution that insists on a universal value for academic writing that she just doesn't buy. Many years ago Adrienne Rich wrote of the dehumanizing effect of college life on struggling students-the registration, the endless administrative bullying, and finally "a semester in courses which they never chose, or in which the pace and allusions of a lecturer are daunting" (61). Students in general, and particularly those in some sense "new" to the academy who often end up in the basic writing classroom, are burdened by disappointments and roadblocks that begin to smack them in the face from the moment they enter college. Meditating on a similar problem of student alienation and disempowerment in the classroom, Ira Shor asks: "With negative feelings smoldering from the Siberian corners [of the classroom] forward, how much performance can we expect [from the students]. . if we pretend their alienation isn't there or that disempowerment is not an issue?" (34). In one light, I can understand Amber's initial attack on paper writing as a complaint about how my course as an institutional requirement creates one more demand on her, one more hoop to jump through that she was not allowed to at least select for herself.

Entertaining such an interpretation (or reinterpretation) of Amber's rebellion against paper writing, I can see that I may have taken the wrong approach in responding to her obviously resistant attitude. What if I had read Amber's objection as an attempt to initiate what Ira Shor calls "power sharing" in the classroom-the process of democratizing classroom discourse and allowing students to actually have a say in what goes on in the class? While the term "power sharing" sometimes names the pedagogical practice of negotiating the curriculum, at the least it usually indicates some nod toward "shared authority or cogovernance" (Shor xi). But more importantly, "power sharing" means allowing our sense of where students must go to give way to an acknowledgment of where they presently are, and how they experience the power exercised over them by the academy while in their current position (as "outsiders" I suppose, but outsiders with immediate social and material interests). Analyzing a debate with his students over attendance requirements, Shor writes:

I suppose that the student dislike of classes and attendance can easily be mistaken as mere anti-intellectualism, or as plain resistance to a required course, or as simple laziness. Some of these conditions no doubt exist. But, there is also a power issue here-the control of time, space, and motion in life. (94)

One could easily insert the issue of paper writing in this passage, if only in 
order to make a very similar observation. In objecting to paper writing, Amber could certainly be objecting to an exertion of power over her-the power to dictate what skills will matter for her in life, which she should presumably agree to pay for, and at which she should try to excel. Viewed in this material context, it should become less important why Amber plagiarized than that she plagiarized at all, and that her doing so was very likely in some way connected (as it would be for most of us) to her lived reality as it came into conflict with academic expectations. In this context, maybe my attempt to "win her over" by speaking in the language and the interests of academic authority was pretty frail. Perhaps she was asking primarily to be heard by the academy, not to be subsumed by it.

You could easily object at this point that I failed to observe some fairly obvious classroom dynamics if I could not intuit from the start that Amber was struggling against academic authority, and you would of course be right. But it was not so much a question of not realizing her struggle, as failing to take that struggle seriously. From one perspective, I am always willing to concede that academic literacy and not "democratic co-governance" is the job at hand for a composition teacher. If you actually succeed in teaching a student to write in "academese" and she still decides to spit on the whole enterprise, maybe that is as much as can be expected from any of us. But that is still to overlook the fact that basic writing programs continue to justify their survival by playing on the common assumption that we do something in the classroom to help students with a few strikes already against them "survive" in college. When working under the rubric of basic writing, I am associating myself with a historical commitment to expanding access in higher education. If I cannot help my students work within the expectations of the university (or change those expectations to suit them), as Amber eventually failed to do, then I am left uncertain that they will be able to reap the benefits of that access. This fact alone makes me more than willing to reconsider how effective my own pedagogy was or could have been in helping a student like Amber achieve those more general goals.

At present, however, many continue to offer variants on a theme of academic repositioning as the best that basic writing can do for the resistant outsiders we govern, and still rarely co-govern. At the moment of Amber's first confrontation with me, it was unfortunately not within my power to stop assigning writing in the writing classroom and take up some other topic Amber found more practical. It might, however, have been possible to explore what kinds of writing she and other students thought would 
evaluate learning more accurately and provide more practical career training. Such a move could begin with syllabus negotiation, a practice Shor describes at length in When Students Have Power. At the start of the semester, I could have invited students to examine the terms of the syllabus, and use their rhetorical savvy to negotiate for ones they judged to be fairer or more educationally productive. This initiating activity in the classroom could potentially function as more than an empty gesture of egalitarianism; it could re-introduce students to the practical value of verbal acumen in a way that is hard for many students to miss. Written work could easily be incorporated in this opening negotiation, to work more closely with skills of exposition and argument. Even more appropriate, when thinking of Amber's situation, I could have created assignments that actually allowed her to direct a critique of paper writing to a larger forum of those responsible for such decisions, teachers and administrators. By encouraging her to write to and for faculty committees, university publications, or even individual professors, I could possibly have helped Amber create rhetorical contexts outside the classroom in which to express her concerns about paper writing and actually have a chance of receiving an authentic response. Expanding the curriculum of basic writing to include public writing tasks seems to me to offer excellent opportunities to tap student "resistance." Offering students contexts for writing beyond the classroom is a simple but powerful way to help them fight their own immediate social and educational battles and simultaneously move them toward a goal of greater academic literacy. Most importantly, it could help the instructor avoid my error: Simply repositioning a student's critique of schooling, rather than helping the student find real ways to use writing to change what she doesn't like about the world.

Critics might describe the "critical gesture" as a key element of discursive authority in academia, the element of our own professional lives through which we feel ourselves to be renegades with a pen, outsiders with the implicit sanction of the inside. But in handing this ideal off to transitioning students, particularly basic writing students, don't we ignore what might matter most, namely, that in order to successfully deploy the critical gesture consistently and use it as a vehicle for self-betterment in higher education, one must first inevitably accept the authority of the "inside" to determine value and meaning? Amber had no problem, in her initial paper, mimicking the critical posture I prompted from her, but it did not change her evaluation of the institution of paper writing in general, which remained skeptical and detached (as suggested by her final act of pla- 
giarism). While her writing evidenced a well-contextualized critical sensibility, her ultimate submission to academic standards of value-and to the academy's right to determine value for her-remained an open question. And thus Amber, as discerningly critical as the day is long, still chose to push herself away from the invitation to academic authority I thought I was offering her.

What if I had incorporated assignments that encouraged Amber to address her concerns to those who might actually be able to change her reality? Could I in a small way have better affirmed her right, not just to raise critical questions on the page, but to question those in authority (both within my classroom and beyond it) about the value of the education she was receiving? Amber came to college as a young adult and first-generation college student, already economically disadvantaged in comparison to many entering first-year students and worried about her future. As Ira Shor notes: "Knowing the unfavorable economic context in which I teach and in which students take the ... class helps me avoid blaming them for "lack of motivation' and for career anxiety which limits their interests in humanities and experimental learning" (37). Likewise, taking more seriously the practical pressures placed on Amber throughout her first semester of college, I might have done more to make writing a tool that helped her cope with them. Recognizing that a student like Amber would have to either submit to those academic values or reject them entirely unless I allowed them to be put into a real dialogue with her own needs and expectations, I might have used my transitory authority over that classroom to make the subject of the course respond more directly to students' immediate needs.

Or maybe that is just another teacherly posture that will be revealed to me eventually as naïve. The important point that my own missteps have revealed to me is that the critical gesture cannot deliver on its promise to empower basic writing students, or any students, if the teaching of it becomes just another way to ignore student voice in the classroom and pretend that any sense of conflict between student experience as "outsiders" and their new "insider" life in the academy can or should be erased. In "Conflict and Struggle," Min-Zhan Lu cautions against the long-standing acculturation mission of basic writing, which tends to view student alienation or cultural clash in the university as a kind of "psychic woe" (48) to be overcome as quickly as possible. I would only add that critical pedagogy seeking to "reposition" the student can perform this same function of masking conflict, if approached too unthinkingly. A key presumption of so much teach- 
ing of basic writing - that we really can and should dictate where these students need to "go," both in their writing and in their transition to higher education in general, and then proceed to take them there-has to be tempered by at least some willingness to share power with those students in any given moment. If that does not happen, students like Amber are likely to recognize (as I think she did, though I can never know for sure) the same one-sided authoritarian dialogue of their previous schooling in play-in which objections may be briefly entertained but nothing that truly matters is ever really up for debate.

\section{Works Cited}

Axelrod, Rise B., and Cooper, Charles R. Reading Critically, Writing Well. $6^{\text {th }}$ ed. New York: Bedford/St. Martins, 2002.

Bartholomae, David, and Anthony R. Petrosky. "Facts, Artifacts, and Counterfacts: A Basic Reading and Writing Course for the College Curriculum." Rpt. in A Sourcebook for Basic Writing Teachers. Ed. Theresa Enos. New York: Random, 1987. 275-306.

Flynn, Elizabeth. "Strategic, Counter-Strategic and Reactive Resistance in the Feminist Classroom." Insurrections: Approaches to Resistance in Composition Studies. Ed. Andrea Greenbaum. Albany: State U of New York P, 2001. 17-34.

Hindman, Jane. "Reinventing the University: Finding the Place for Basic Writers." Journal of Basic Writing 12 (1993): 55-75.

Lu, Min-Zhan. "Conflict and Struggle: The Enemies or Preconditions of Basic Writing?” College English 54 (1992): 887-913.

Rich, Adrienne. "Teaching Language in Open Admissions."On Lies, Secrets, and Silence: Selected Prose 1960-1978. New York: Norton, 1979. 51-68.

Shor, Ira. When Students Have Power: Negotiating Authority in Critical Pedagogy. Chicago: U of Chicago P, 1996.

Trimbur, John. "Resistance as a Tragic Trope." Insurrections: Approaches to Resistance in Composition Studies. Ed. Andrea Greenbaum. Albany: State U of New York P, 2001. 3-15. 


\title{
Rethinking Language and Culture on the
}

\section{Institutional Borderland}

\author{
Virginia Crisco
}

ABSTRACT: Previous ethnographic pedagogical approaches in basic writing classrooms emphasized students' acculturation into academic discourse; however, teachers' critical reflection should also consider how exposure to students' experiences intervenes in and informs pedagogical practices. In this article, I argue that teachers should listen to their students in order to take a critical approach toward institutional change. I focus specifically on a basic writing class composed mostly of Latino students to understand their experiences of being bilingual in the academy. Listening to these students led me to consider not only how to create pedagogical change but also to propose processes for institutional change as well.

If you became too much trapped in this new language, you begin to loose your original language. You will start seeing the world in an Anglo point of view. You will only do things that are considered to be appropriate in the Anglo culture.[. . .] Your old traditions and beliefs might be replaced with new ones. The more and more you speak English the more and more you will start acting like what you consider your peers.

- Jose, ${ }^{1}$ basic writing student

So if you really want to hurt me, talk badly about my language. Ethnic identity is twin skin to linguistic identity-I am my language. Until I can take pride in my language, I cannot take pride in myself.

-Gloria Anzaldúa,

"How to Tame a Wild Tongue" (59)

The epigraphs by Jose, a basic writing student, and Gloria Anzaldua, a Chicana writer and poet, call attention to the effects of language and language assimilation on a person's identity and sense of self. Jose equates learning another language and ideology with the "Anglo point of view." He suggests that when the Anglo ideology is valued too much, a person

Virginia Crisco is a doctoral candidate in Rhetoric and Composition at the University of Nebraska-Lincoln, where she teaches courses in writing, rhetoric, and English Studies. Her interest in the intersections of ethnicity, language, and Basic Writing started at California State University-Fresno, where she received her Master's degree in Composition Theory. She is currently working on her dissertation, which examines the pedagogical implications for literacy learning through democratic processes that occur in the classroom and the community. 
will forget their native culture. He uses the metaphor of being "trapped" to discuss a person's reaction to conflicting language and viewpoints.

Anzaldúa argues in "How to Tame a Wild Tongue" that assimilation creates prejudice and goes on to suggest that prejudice has an effect on Chicano/a identity. She writes, "Chicanos and other people of color suffer economically for not acculturating. This voluntary (yet forced) alienation makes for psychological conflict, a kind of dual identity - we don't identify with the Anglo-American cultural values and we don't totally identify with the Mexican cultural values" (85). Anzaldúa exposes the complex nature of cultural conflict, which may provide some insight into students' conflict with language and acculturation in the writing classroom.

Teachers and researchers have proposed to address this issue of assimilation by bridging the gap between the student's home community and the academic community through ethnographic research and writing. As discussed by Shirley Brice Heath and by Eleanor Kutz, Suzie Groden, and Vivian Zamel, ethnographic research and writing ask students to start with what they know and then do research and present that knowledge in a genre of writing that has roots in the academy. As Kutz, Groden, and Zamel hypothesize:

One of our assumptions, and we still believe a correct one, was that we could draw on our students' knowledge of their experience and their competence with language to establish a base for building new areas of knowledge and competence. A related assumption was that we could elicit that competence directly through the tasks we designed, allowing the students to transfer what they knew from the larger world to the work of the college classroom. (88)

The work of Kutz, Groden, and Zamel is particularly valuable because it asks teachers to recognize students' competence to think critically in everyday life. Their work is also important because it demonstrates that students can excel at writing by tapping into this competence and shaping it into a form and language that are acceptable to the academic institution. Finally, Kutz and her co-authors also explain how teachers of writing can learn about English language learners' experiences from their writing and then revise pedagogical approaches to better address students' needs. More recently, Mary Soliday, in her essay "The Politics of Difference," considers what literacy narratives can teach teachers about the diverse goals students of color bring into the classroom. She ends her essay by arguing that "In 
the classroom, we can best approximate inclusive images of multiculturalism by promoting a dialogue that moves between students' worlds and ours to illuminate connections as well as highlight differences" (272). Soliday's work makes it clear that students have different agendas for their education and thus have different needs in the writing classroom. All of these teacher/scholars advocate for a cultural bridge where students' experiences are valued and necessary to the work of writing.

Too often, though, such pedagogical approaches don't take into account the institutional challenges students face. The assumption that teachers and writers make is that the cultural bridge does not go beyond the classroom or the teacher, and the change that is called for is a pedagogical change focused on how the teacher can work with students more effectively. In this case, the point of "bridging" the writing classroom with what students know, or "building new areas of knowledge" (Kutz et al. 88) is for the student to "transfer what they kn[o]w" (Kutz et al. 88) into academic genres and languages. Soliday, in addition, calls for "inclusive images of multiculturalism," an accounting for difference that blends with the current dominant culture-while leaving the dominant culture the same-instead of changing attitudes about how difference is valued. In fact, Keith Gilyard, in Race, Rhetoric, and Composition, argues that even with the advent of multicultural education, composition as a field is still working toward anti-racist pedagogies: "Even as our profession largely converted to multiculturalism in the $1980 \mathrm{~s}$ $[\ldots]$ it was apparent that composition instructors as a whole had not confronted deeply enough issues of race, racism, and racialized discourse. [...] Multiculturalism, then, with its characteristic emphasis on rather low-level sensitivity training, serves to obscure the problematics of racism [...]" (47). If we do not confront the institutional structures that privilege white, English-speaking teachers and students, we will not be able to move forward in our field's desire for welcoming, addressing the needs of, and working toward equality for students of color in college writing classrooms.

This article focuses on the institutional requirements and political contexts in one basic writing classroom at one California State University and on the students' reaction to those requirements and contexts. I draw on a classroom composed mostly of Mexican American ${ }^{2}$ students to illustrate how language, identity, and institutional structures intersect as manifested in these students' ethnographic writing. This intersection not only positions teachers and students to create pedagogical change, but also challenges us to use our respective knowledge about language and rhetoric 
to change the institution as well. More specifically, this article will draw on bilingual students' ethnographic essays to demonstrate how their knowledge about language and learning represents their positions in the academic institution. Overall, I propose that students' ethnographic essays provide a dual function: first, they offer opportunities for students to observe cultures in order to better understand and represent them in an academic context; and second, ethnographic writing gives teachers an opportunity to listen-critically-to students, to understand how students are situated in the power structures of our institutions. In the end, the work of this article becomes a call for teachers, not just students, to listen, learn about, and, gradually, change the institutional spaces that dismiss students' differences. Institutional change is one of the hardest tasks to undertake, but change can only happen if we start somewhere and take one step at a time.

\section{Institutions of Language and Writing}

Now I have a daughter. She is one year old. I talk to her in both languages. But my social worker asked me in which language do you talk to your girl? I said in both languages, and she told me you should speak to her only in English because we are in America.

-Rosa, basic writing student

Like my mother says, we are in the United States and in order to improve our skills and be successful we need to learn English. [It] is good to learn English but also others need to respect people who speak another language.

-Lupe, basic writing student

Linguistic imperialism has a long history in California and in the public policy and education systems of this region. This history is important to composition because the historical treatment of particular social groups becomes infused in institutions and informs how people are treated long after the particular historical moment is over. One piece of evidence in this regard is the comment by Rosa quoted above. Rosa's social worker expects her to teach her daughter English only "because we are in America." The assumption this social worker makes is that even in the private spaces of the home, Rosa's Spanish language should be pushed aside in favor of the dominant culture's language practices. On the other hand, Lupe's mother believes that Spanish speakers should learn English. But Lupe then argues that speakers of other languages should also be respected, 
implying that they currently are not. Rosa's social worker may believe that she has Rosa's daughter's best interests in mind. On the other hand, the social worker might not realize how her response to Rosa reinforces institutional ideas about assimilation. She also might not realize how this response is constructed historically as the only option for speakers of other languages in the United States.

In "Spanish in California: A Historical Perspective," Alexander Sapiens delineates a history of the politics of Spanish speaking and learning from 1769 to the 1970s. Again and again, policy in California was passed that denied Spanish speakers' rights to vote, to become educated, and to become citizens. In fact, Sapiens writes, "The history of education and language policy of the Chicano in California has been dominated by discrimination, segregation, exclusion, and neglect" (81). In 1849, after the Mexican-American war, American public schools replaced the Spanishlanguage schools within one decade. In 1855, state law required that English was to be the only language used in the public schools, and in 1879, English was declared the official language of California. This history demonstrates California's institutional expectations for Latino/a assimilation to the dominant culture and to the rendering of Spanish signifying practices as impertinent to the institution; all of this occurred despite the fact that, according to Rodolfo Acuña in Occupied America, the Mexican American border moved, yet the Mexican people did not.

More recently, California voters decided, once again, to vote for assimilation at the expense of bilingual education. The Unz initiative, passed by a majority of voters in June 1998, states that "All children in California public schools shall be taught English by being taught in English. [.. .] this shall require that all children be placed in English speaking classrooms." The passing of this proposition represents voters' desire for non-English speakers to assimilate to the "norm" of English speaking in the institutions of the state. But this focus on teaching English Only is not specific to policy. Bruce Horner and John Trimbur argue in a recent College Composition and Communication article that courses in college composition have been historically constructed as monolingual as well: "the historical formation of the first-year composition course is tied in tightly to a monolingual and unidirectional language policy that makes English the vehicle for writing instruction in the modern curriculum" (623).

The historical context discussed above is presently enacted in state and educational institutions and creates a conflict for students between their 
desire for cultural assimilation and pride in their native culture. Tom Fox characterizes this conflict as a struggle that positions students in particular ways as learners and citizens. He writes, "Examples of powerful writing for social action make the point to students that the opposition between 'literacy' and the 'academy' is not one of discourse form, nor is the opposition simply 'oral' versus 'literate' or 'street' versus 'school.' Instead it is the struggle for equality and access" (102). The struggle for equality and access is represented through laws created to encourage assimilation, laws that force students to learn English in public institutions. This struggle can also be characterized by what is taught in the classroom and what expectations the institution has for its teacher and student participants.

Language and institutional context doubly marginalize Latino basic writers, challenging them to learn the norms of the institution as well as the English language without valuing the diversity and knowledge they bring to the academic context. Basic writing scholars and pedagogues have done their best to subvert this type of marginalization by building on the knowledge students bring and by supporting students with pedagogical approaches that treat them like learners and thinkers. But there is one major component of such theories and approaches toward learning that is missing: students' experiences of being in the academic institution. What can our students teach us about their language, identity, and institutional context? What is our responsibility, as teachers of writing, to consider students' perspectives and to act on them in ways that support a critical understanding of difference in our classrooms and our institutions?

\section{A Context for Basic Writing}

This history of linguistic domination and institutional assimilation is still felt by the students who come to the university, a place, many argue may be the pinnacle of privileged, English-speaking values. At the university where I taught basic writing, California State University-Fresno, the student population is very diverse. According to the enrollment statistics for the 1999-2000 school year, "Minority groups represent more than half of the CSU student body, double the national average" (California State University Public Affairs Office). California State University-Fresno, otherwise known as Fresno State, is a land-grant institution in the heart of the San Joaquin Valley. The valley, one of the most productive in the world, grows many different vegetables, nuts, and fruits. Because of the amount 
of agriculture, there is a high demand for farm labor, bringing in large migrant populations. Most students are from California because, for one thing, the state universities have promised to automatically accept the top one-third of the state's high school graduates. Most of the buildings on campus are made of cement, with the one brick building being the library. The two statues situated outside the library are bronze representations of Caesar Chavez, best known for his activism for migrant labor rights, and Mahatma Gandhi. Students who enroll in the university come from ethnic backgrounds including Mexican, Laotian, Thai, Hmong, Vietnamese, Filipino, Punjabi, African American, Euro-American, Armenian, Native American, and El Salvadorian. International students are present as well from such countries as China, Japan, and Malaysia. Though this article focuses on Latino students, my call for action could benefit students from a variety of cultures.

The particular basic writing class I focus on was made up of 17 students; 13 students identified themselves as having Mexican origins while 4 students identified themselves as having Filipino (1), black (2), and white (1) cultures/races. In relation to the languages spoken by all students, 3 students were born in the United States and spoke English as their native language; 4 students were born in the United States and spoke Spanish as their native language and English as a second language; 7 students were born in Mexico and moved to the United States around high school (they had been learning and practicing English for 6 years or less), and 2 students were born in other countries, specifically, Mexico and the Philippines, and moved to the United States when they were very young. Though the class seemed homogeneous in that the majority of students identified themselves as Mexican Americans, in actuality, there was much diversity in their experiences and thinking about language. For my purposes here, I focus on students who were born in the United States, spoke Spanish as their first language, and learned English in the public school system. These students had had experience in the U.S. education system and had learned and used both languages regularly; they also had definite opinions about educational policy. In addition, these students provided me with the impetus to take responsibility for the cultural information and attitudes I asked students to bring into the classroom.

When students are asked to write ethnographic texts, the teacher has an opportunity to listen to the conflicts students face in the Englishspeaking institution. As Suresh Canagarajah suggests in Resisting Linguistic 
Imperialism in English Teaching, ethnographic teacher-research provides teachers with 1) an introduction to students' vernacular; 2) the ability to see one's own culture through students' eyes, and therefore to locate and examine the teacher's or the student's position within the hegemony; and 3 ) the ability to become a border crosser with students, to confront and negotiate the various discourses and ideologies that a person faces in a multicultural social structure. In the next section, I focus primarily on point number 2: students taught me to see one of the cultures I represent and identify with-Composition and Standard Written English in the academic institution-as they experienced this culture in my classroom; their ethnographic representations helped me to understand the institutional discrimination they faced because of the languages they spoke and the cultures they identified with.

The student writing I consider below represents the attitudes and experiences of Mexican American students who have decided to go to the university, but who also face conflicts between the expectations of the university environment and their ethnic and linguistic background. The students' writing indicates reasons for the existence of this conflict, describes ways students deal with the conflict, and suggests possibilities for facilitating learning between students and teachers. In the end, the information given to me by students caused me to think about how to sponsor larger changes both inside and outside of the classroom.

\section{Students' Experiences of the Academic Institution}

The writing that I will draw on in this section comes out of the writing projects students did for the class, four in all. The course topics and corresponding writing projects focused, overall, on the different choices we make with communication. More importantly, I asked students to consider how those choices are connected to language use and are caught up in cultural and social hierarchies. The first assignment was specifically about the folklore of their culture. Students were asked to write and analyze an oral story. Research on this topic included interviewing parents or siblings or observing the kinds of stories told in the student's or perhaps a relative's home. The class read and discussed "Stories" by Phyllis Barber, an essay focusing on the traditions and storytelling that surround Christmas in one particular family, and "Language and Literature from a Pueblo Indian Perspective" by Leslie Marmon Silko, focusing on the 
significance of storytelling in Native American culture. Our discussion of these essays related to the types and purposes of oral stories, the communication of oral tradition within a variety of cultures, and the representation of oral stories to the family or other social group. Students were pushed to write an accurate and complete story and to analyze the story by making connections between the context of the story and the relationship of that story to their culture or to storytelling.

The second assignment asked students to research a discourse community they belonged to. In our discussions of oral stories, I introduced the class to the concept of discourse communities and asked them to start thinking about the variety of discourses they come in contact with. I asked students to record or take notes on actual conversations in order to do this work. Students read "How to Tame a Wild Tongue" by Gloria Anzaldúa and "Nobody Mean More to Me Than You" by June Jordan. These essays provided names for the different discourse communities people belong to and also modeled the rhetorical process of including written language as evidence in the body of a text. This writing project assignment was designed to get students to name the variety of discourses we learn and use on a regular basis as well as to analyze the power dynamics that are within a group or that put pressure on the group from another discourse community. I asked students to observe and record a conversation to find answers to questions about the language choices other people (and they) make in particular circumstances. Students were encouraged to ask questions about how language works within different contexts and to analyze the effect of their own language choices. In their writing, I asked them to include actual examples of language and pushed them to analyze people's discourse choices depending on the communication context.

In the third writing project, I wanted students to look more closely at the process and politics of writing. I asked students to collect written artifacts and then analyze written discourse as a form of communication. I encouraged them to search for sources of their own or others' writing outside of the context of school, but I also suggested that they could reread chat and e-mail transcripts from class and use their observation/reflections for this writing project assignment. As a class, we read Fan Shen's essay, "The Classroom and the Wider Culture: Identity as a Key to Learning English Composition," which focuses on Shen's observations of different types of acceptable writing in the American and Chinese cultures. We also read an excerpt from Shirley Brice Heath's book Ways with Words to demonstrate 
the different types of writing people do; after the students had read this excerpt, I asked them to consider when and why they practice these different kinds of writing and to observe the dynamics of who in the family did the most writing. The excerpt from Ways with Words gave us an opportunity to discuss this text rhetorically, as well, to use it to help us further define approaches toward writing ethnographic research. The class discussion focused on how one's education or family influence literacy as well as the changes one necessarily makes when moving into an unfamiliar context. Students were pushed to analyze how we represent ourselves on paper, why we make a choice to communicate through writing, and how we relate to our audience through writing.

Students built on their knowledge of different languages and choices made in written and spoken communication by finally researching how people interact within a community. For the last writing project, I asked students to observe classroom collaborative situations. To set students up for this work, I had them reflect at various moments during the course on the group dynamics they were experiencing in class. In addition, I assigned specific readings to prepare students to think about this work. We discussed gender issues relating to group dynamics in the essays "Anna" by Elizabeth Chiseri-Strater, and “Teachers' Classroom Strategies Should Recognize that Men and Women Use Language Differently" by Deborah Tannen. Within the context of the course, we discussed changes in personal behavior within small groups, large groups, chat rooms, various classroom situations, and within culture or gender groups. Students were pushed to recognize what conditions were necessary for group dynamics to work or fail and to analyze how people worked as a group to make changes. The course readings, writing projects, and conversations led us to learn from one another, helped us to understand one another's experiences with language and communication, and, overall, demonstrated to all of us where and how students were situated in the various aspects of their lives.

To begin to understand the cultural and institutional conflicts students face, we should start with the conflict between the English and Spanish languages, an issue which often surfaced in my students' writing projects. Ethnographic writing can be particularly important in identifying and analyzing this conflict because it can position students to draw from their experiences as language users; it can also place those experiences in an academic context and demonstrate how academic language and writing is positioned within their experiences. This gives teachers a window into 
the conflict students face in their desire to succeed with academic language in contrast to the desire to respect and hold onto the language of their heritage.

Many of the students' parents do not want to see their children lose their culture, as one of my students observed; so parents expect students to keep their culture by, for example, asking their children to speak only Spanish in the home. Beatrice, for example, wrote an essay about the relationship between writing and culture in which she tells how important her culture is to her family members and articulates how far they would go to keep their culture alive in their children. In this essay, she says that she wishes to show her parents her school writing. She does not, however, because her parents do not speak English. In the following section, she reflects on why her parents have not learned English:

Maybe part of the reason for not doing so was because they thought that by learning a language other than their own, they felt like they would be putting their culture and beliefs aside, that maybe if they did learn a different language they would become Americanized and they didn't want that not from them and especially not from us. That is why my parents have always asked us to speak Spanish in front of them.

Beatrice's writing suggests that language and culture are closely connected. For her parents, she speculates, the choice of using one language instead of another represents a certain loyalty to a particular culture and beliefs. She also makes clear that becoming Americanized is not a valued goal for her and her family members. Beatrice does not want to become Americanized because, to her, that would mean giving up her culture; she wants to be successful in the American culture, but she does not want to give up her Mexican culture. Beatrice's parents are fighting to keep Beatrice and their other children from losing their culture to others' imposed expectations of being a part of the dominant American culture. Implicit in this conflict is the idea that if one is American, one cannot be Mexican. Beatrice's experience indicates the pressure she feels between a desire to be successful in the American educational institution and the desire to identify with her family heritage.

Beatrice's experience is not anomalous. Many students discussed the pressures they felt to respect and hold onto their heritage and to be able to imagine success through conforming to the dominant culture and 
language. On the one hand, parents want the younger generation to succeed in the dominant American culture by getting a higher education in English-speaking institutions. They know that the way to imagine a different life for their children is to encourage them to learn English and go to school in the United States. On the other hand, parents don't want their children to believe that their heritage and culture are any less valuable than the dominant culture. In Susana's case, she discusses how these pressures are manifested in her home. In an essay entitled "Another Regular Day," Susana writes about the different language groups she is a part of and how these groups expect different things from her. In the section quoted below, she writes about the language-using practices of her family:

As we sit on the porch of our house having a glass of water, my parents describe to me their exhausted day at work. They are communicating to me in the only language they know, which is Spanish. As we speak we can easily understand and joke about what is being said. "It is important to always keep your culture alive," my mother states. Although my parents are supposed to be supportive of us children, my parents did not have the opportunity to teach me English. As for themselves, working to support the family was their number one concern. It made it harder for me to learn English as I began school. Since they were always busy expecting me to speak to them in Spanish, it never inspired them to learn the English language.

This section of Susana's essay is rife with conflict. Susana's parents want her to keep her culture alive, as her mother says to her explicitly, suggesting that Susana faces the possibility of losing her culture in some way. Susana also seems to be conflicted because she had a hard time learning English and her parents were not able to help her. On the one hand, she suggests that it is because they needed to focus on supporting the family economically; on the other hand, she seems annoyed that they were so caught up in wanting Susana to keep her culture that they were not able to help when she faced the huge challenge of learning English.

What the experiences of Beatrice and Susana demonstrate are the pressures to be both English-speaking and Spanish-speaking, to know the dominant American culture and to know the Mexican culture. Both Beatrice and Susana want to be successful in higher education and want to be able to share their successes with their families. They also want to respect 
the culture of their families and demonstrate to their parents that they haven't lost their identity as it is constructed through their heritage and language. Because the academic institution expects students to learn English and become a part of the dominant American culture, and because this institution provides the opportunity for students to imagine a different kind of life from what their parents may have had, students face a conflict as it is represented in language. In this conflict, students feel that they must choose one culture and language over the other. The problem with this scenario is that the richness of students' lives is ignored at the expense of upholding the cultural status quo of the institution. Because students cannot bridge their home community and the academic community easily, a conflict arises that pits the goals of these two language groups against each other.

Because I can mark language terrain as either Spanish or English, as I did above, I am able to talk about the conflict students face in bridging one set of language-using practices with the language-using practices of the academic institution. In reality, language as it is practiced in communities is not necessarily so monolithic, meaning that these communities are not fixed and unified. Instead, I would like to argue that students have multiple identities and have access to various language practices that are not necessarily finite and fixed but rather flexible and overlapping. As I asked students to do ethnographic research on their own language communities, I was able to better understand, from their perspective, the richness of their language experiences and the different rhetorical challenges they faced in the variety of discourse communities to which they belonged. My students' ethnographic writings provided me with insight into the abilities my students had with language in various contexts and demonstrated to me how authority affected those contexts. As I will demonstrate below, language hierarchies, and those who support and enforce hierarchies between languages, do not create productive learning and communication environments and do not allow for the various ways languages can be useful in various contexts.

Most interesting in the students' ethnographic research was an emphasis on the connections between language and how language-using practices are embedded in power structures. Many students spoke about belonging to at least three different language communities involving English, Spanish, and Spanglish. Spanglish, according to Jose, is a language created by the Chicano culture mixing English and Spanish words. Chicanos are people of Mexican descent who are living in America, who want to de- 
fine themselves as a group; they are Mexican, and they are American, but they cannot be only one or the other. One problem Chicanos face, according to Jose, relates to the language they use to represent themselves. Jose observes in his ethnographic essay titled "Spanglish" that this language is not valued by the English- or the Spanish-speaking cultures, as it is a mixture of both languages and not a pure form:

[Spanglish] is looked down as, "slang talk", that is used only by the uneducated and lower class people.[ . . . I I remember as a youngster playing marbles with a few of my cousins who had just moved here to California from Mexico. One of them cheated so I called him a chirion. They had never heard that word before so they started laughing. [. . .] As far as I knew it I was speaking in Spanish but to them it did not seem as so. This was the only form of Spanish I knew. So now I found myself trapped between the Spanish and English culture. I was looked down in both the American culture and Mexican culture.

Jose then suggests that some people want Spanglish to be eliminated as a communication style and goes on to write, "stripping one completely of their communication style is like taking their culture away too. [...] in many cases this is the only piece of Mexican culture the Chicano people have." Jose explicitly demonstrates how cultural identifications shift based on context and language-using practices. Importantly, he also discusses the hierarchy involved in cultural identity and language use. The implication of this essay, an implication that Jose argues against, is that the only legitimate form of a language is a "pure" form; thus, the only legitimate form of a culture is a "pure" form. His argument is to legitimize this hybrid language because it represents a particular culture that is important to him and to others; it represents a group of people who have created their own common identity because of their similar circumstances in the in-between spaces of language communities. Certainly, this issue of legitimacy, where teachers, schools, and state law require standard written English only, is also present in academic institutions, specifically basic writing classes, as this is the place where students are to be socialized to become full members of the academic institution.

In their rhetorical essays, students described certain language-using practices as privileged in certain spaces. This demonstrated to me that the decision to shift languages was not always a rhetorical choice; instead these 
shifts were based on institutional history of what is acceptable in a certain space. Yasmin reports on three different discourse communities that she belongs to and argues, in her ethnographic essay on language groups, that she feels "split into two different people by speaking one language in one place and having to change my language to English with others." In the final draft of her essay titled "Two Speech Communities within One," she writes:

I guess the professor feels that we also should speak a certain language depending on the surroundings. Like if we are with our parents you can speak Spanish. But if we are in the library, we should speak English, because it's disrespectful for those who don't understand the Spanish language. So, I only speak English for everyone at school, so all can understand me.

In this essay, Yasmin articulates how she has been told what language to use by her professor. The professor imposes particular language choices on Yasmin so that others don't feel left out because they can't understand. Yasmin says that this professor's purpose is to get her to be rhetorically effective, to use the language that people understand in a particular context. Interestingly, she says later that being in the library is enough to cause her to speak English only in case others around her don't understand what she is saying. The implication of the professor's statement is that because English is the dominant language, everyone else should speak English. There is no sense that if the professor-or another in the librarywants to understand Spanish, then that person should take it upon him or herself to learn that language. Instead, because the academic institution is regulated and historically constructed as purely English speaking, then the professor has a right to tell Yasmin what language to speak in particular institutional spaces.

Both Jose's and Yasmin's essays discuss how their languages and identities are regulated and informed by those who hold onto hierarchies of language-using practices. In both of these situations, students are put down because of the various languages they have access to. They find that certain language-using practices are not valuable in certain spaces and with certain people. Listening to Yasmin's and Jose's experiences with forms of language use has helped me to understand how dominant ideas about language are manifested in many different contexts. These dominant ideas reproduce institutional notions of appropriate language use and suggest 


\section{Virginia Crisco}

that there is only one proper way-rather than many-to communicate in different contexts. What would it be like if our institutions of higher education encouraged all students to speak more than one language? What would it be like if institutions of higher education made a space for different identities, languages, and beliefs? What would it be like if the languageusing practices sanctioned by the institution really represented rhetorical choice rather than the dominant culture?

Because very narrow visions of culture and language are acceptable in the institution, students feared that they would never be able to meet institutional expectations, and if they tried, they would have to give up part of who they were. The students' ethnographic texts helped me to understand the expectations they faced from the institution as well as how they felt they could meet those expectations. Susana writes about the difficulties non-native speakers of English face when they learn to write in an academic institution. She does this by drawing on Fan Shen's essay "The Classroom and the Wider Culture," and goes on to argue that people who are not from the dominant American culture cannot ever completely assimilate:

Everyone today expects everyone to learn the Anglo-American way of values. It is hard for people to do this especially for people who emigrate from a new country. I feel that only to a certain extent you can learn to think as an Anglo-American, which makes it hard for a person to have good English composition. Still people can learn a lot but if not well known, it will of course never be perfect. Pronunciations and ways of thinking will always be different.

In the first sentence Susana refers to the pervasiveness of the expectations to follow the "Anglo-American way of values." These values are the norm; everyone is expected to know them and abide by them. Basically, these values are defined, in this context, as values that influence writing, thinking, and language use. Susana implies that non-Anglo and non-native speakers of English will never be able to meet the requisite standards of written and spoken English, at least not as manifested at the university. This demonstrates that Susana feels she will never be able to think, write, or speak like a native language user in English-speaking institutions. How hard would it be to know that you could never be as proficient in writing and language use as your Anglo counterparts? 
Jose also discusses the difficulties he faces because of not being able to completely assimilate, but then he goes on to argue that in even trying to assume a new set of values, a person necessarily has to give up another part of him or herself. Jose writes about this experience in an essay that explores the relationship of culture to writing. Jose explains the difficulties he faced in moving from the Mexican culture and language to the dominant American culture and language. Moving between two culturesas they are represented through language-made him question his desire to belong to the dominant community:

When learning the rules of English composition you absorb new values. Maybe the English you learn is a high-class language where high sophisticated words are always used. You begin to use these words too and at the same time learn the new values of high class. You begin to think like they think and see everything the way they see it. Everything they say is true to you because after all they are high class.

Jose understands that language is not monolithic but connects to culture and class. He describes how a person becomes socialized through the language valued by a particular group of people. He relates this perspective with class, calling the language and the people who use the language "high class." Jose also recognizes that because the people who use this language are high class and sophisticated, what they say seems like truth; it seems that there are no other possibilities for writing and using language legitimately. Jose not only understands the politics of giving up something to get something else, but also understands how such choices are often based in power structures that place language and values within a hierarchy.

Both Susana and Jose recognize the consequences and the reality of trying to assume particular values and trying to replace or augment a previous set of values. Many students want to be successful in the academy but feel that they can never be up to par. Or they feel that in order to be successful they will have to make major sacrifices. Many students don't even question the values expressed in writing classrooms and educational institutions because these spaces have a kind of status that seems to be beyond criticism. So what would happen if not just Mexican American students, and not just students of color, but all students were asked to give up a part of themselves to be successful in the academy? What would happen if all students and 
teachers, in Suresh Canagarajah's terms, had to learn to be "border crossers," had to learn how to "negotiate competing discourses and cultures" (194)? What would happen, finally, if academic institutions were open toand dependent upon-critique and change?

Overall, the themes students discuss are reminiscent of issues brought up in Gloria Anzaldua's book Borderlands/La Frontera. Anzaldua's answer, to the Chicano, is to embrace the mestiza consciousness, the ambiguity that comes from being a part of two (or more) cultures. More recently, Emma Perez articulates the concept of the decolonial imaginary subject, a subject who finds a third space, a space to negotiate new histories and new identity. In fact, many, such as Michel de Certeau, have argued that being on the borderlands or in a third space can provide students with unique possibilities to fight back and make change. But an essential component to this decolonial imaginary subject is being heard. Thus, this is the challenge: how am I, as a teacher, listening to my students? How do I understand what students are telling me about their identity, their experiences with language and learning? In addition, as a white teacher, and as a representative of the institution-a gatekeeper, if you will-I wonder to what extent I am responsible for the issues that students bring up in their writing. How am I also implicated and what is my responsibility in the struggle for student equality through acknowledging and valuing their ethnic identity and language?

\section{Toward Teacher and Student Activism}

So what do we do with the writing students bring to the classroom that focuses on their experiences with language and identity? One of my most significant observations about bringing culture in to the classroom is that this knowledge does not come wrapped in a tidy package. Students don't just talk about the great food or rituals of their culture; they also bring with them attitudes, assumptions, and accusations that may conflict directly with the institutional values I represent, the standardized written English I am expected to teach. As a teacher, then, how do I respond or act, when Jose, for example, says, "The English only proposition for the government, or whoever supports it, wants to take our culture away," or when Beatrice says, "The only way to learn English is to practice as much as you can, although no one should deny you the right to speak your language," or when Yasmin says, "Our professors say that we need to practice more our English. [. . . I I guess the professor feels that he's being 
isolated from this community and wants us to speak in the community he understands: English." These students all speak with anger about being forced to ignore the discourses they are proud of, to speak the valued languages of the academy only. In the end, I agree with Shari Stenberg, who in her essay "Learning to Change" argues for a pedagogy that is messy rather than neat: "Two-way dynamics, where our students exert pressure on our assumptions, our values, our practices, require constant, messy negotiations. But it is only in this ongoing, mutual mess-making that genuine development-on the part of the teacher, the student, and the pedagogy-occurs" (53).

By both listening to and reflecting on students' experiences within the institutional contexts of language regulation and acculturation, I have recognized the limits of my knowing. Listening to the students' experiences and knowledge about language and institutional context has helped me to reflect on what I could do differently in the future. If it is important to me for students to practice the English language and to value that practice, and if it is important for me to respect students' language and culture, the question becomes how to negotiate these seemingly conflicting viewpoints. Because I believe taking action within the institution helps a person to move beyond authoritative structures that may hold them back, the future of negotiating similar language and cultural conflicts from a critical pedagogical perspective lies in the teacher's willingness to recognize what she doesn't know and provide students with an opportunity to learn through their own activism.

In order for the change process to begin, we must consider how teachers' and students' work together can be a catalyst in pressing institutional change. As Tom Fox argues, "Solutions to the 'clash of cultural style' explanation usually involve new consciousness on the part of the teacher, rather than attending to larger social and political changes" (60). In order to go beyond what the teacher has learned to how the teacher is listening, championing institutional change, and supporting her students in this change process, there are questions that need to be considered. How can classroom actions, teacher awareness, and student and teacher activism lead to bigger societal changes, changes that show respect for other cultures, changes that rethink assimilative mandates that all people who live in the United States must be the same?

Institutional change relies on the actions of the people who participate in the institution, whether they are students, teachers, 
administrators, or staff. Bruce Horner and John Trimbur argue that composition courses are important spaces for making institutional change:

Alternatively, we might argue that composition courses and programs provide crucial opportunities for rethinking writing in the academy and elsewhere: spaces and times for students and teachers both to rethink what academic work might mean and be-who is and should be involved, the forms that work might take, the ends it might pursue, the practices that define it and which might be redefined. (621)

Redefining the work that we do in the composition classroom can start with service learning projects that get students-with the teacher's help-out into the community to learn activist literacy processes toward the goal of institutional change. This is not to suggest that students don't already know how to be activists. Instead it is an opportunity for students to develop new processes for activism through writing. As teachers, one way we could support this work is to sponsor community action as a result of the ethnographic work students take on. Currently, I am working with a writing assignment I call a community action project where students use writing to address an issue that is important to them and their community, to weigh in and act on that issue. I preface the community action project with an ethnographic assignment where the purpose is to inquire into an issue facing a community that is important to the students; they are able to observe a community organization, interview people who are affected by this issue, research this issue in newspapers or other local publications. Once their research is done, they can use that research to somehow take action through writing. In my classes, students are strongly encouraged to do this work collaboratively and are given several examples of what they could do-for example, 1) write a letter to the editor, a dean, a congressional representative, 2) write a proposal for an event and then create flyers, signs, and/or press releases to be displayed in a public place, 3 ) design and write materials (i.e., a newsletter, brochures, promotional or educational letters, manuals, etc.) for an organization, or 4) write a "personal" action that might include writing a letter to people close to you explaining a tough decision you made for yourself.

I encourage students to write in the genre, for the audience, and with a purpose that would be most rhetorically effective in their particular circumstance. The community action project helps students to explore new 
territories for democratic participation by finding out who to write to in institutions that represent them and their communities. They figure out which newspapers would have their best audience and how to submit letters to the editor. They look up state laws and learn about university budgets. They present themselves and their arguments for change to new and different groups of people. They consider the arguments of people who don't agree with them. They also find out what kind of impact their writing can have and what venue can be most effective, especially when they get their writing published (or not). Students in the past have written university and local newspapers about, for example, who is allowed to use the word "nigga," budget cuts at the university, and the problems with criticism of gay marriage laws. Students have written and performed slam poetry on losing a girlfriend, and the politics of being a Latino or a woman. Students have written personal actions to their parents asking them to reconsider their opinions about their son's and daughter's interracial relationships, for example.

With the institutional and cultural knowledge teachers have, they can support students in finding the right genres and audiences to get their ideas heard. In addition, students define for themselves what issues they want to focus on and are able to be agents in making that change. In asking students to use writing to make change, I am subverting institutional requirements that ask the teacher to teach students how to write for the academy only, to prepare students, as in the case of basic writers, to succeed in upper division courses. ${ }^{3}$ Instead, I am asking students to determine what issues are important, tangible, and can be changed. In this way, I am not asking students to appropriate academic discourse(s) in order to come over to "our side." Instead, I become an accomplice in the change process. By listening to students, I help them brainstorm issues that might be important to them. I help them find out whom to write to. I help them to make their arguments more pressing to readers.

But students shouldn't be the only agents of change in the institution. Teachers should work toward change as well. ${ }^{4}$ In my role as an Associate Coordinator of Composition at the University of Nebraska, I have taken my work with basic writing students at California State University at Fresno seriously. As part of the job is to support incoming Teaching Assistants (TAs), some of whom are new to teaching and all of whom want to be successful teachers, I have used my position - in collaboration with Maria Montaperto and Amy Goodburn, Associate Coordinator of Composition and Coordina- 
racial categories and should focus on the various differences we all bring to the classroom.

\section{Works Cited}

Acuña, Rodolfo. Occupied America: A History of Chicanos. $2^{\text {nd }}$ ed. New York: Harper and Row, 1981.

Anzaldúa, Gloria. "How to Tame a Wild Tongue." Borderlands/La Frontera: The New Mestiza. San Francisco: Aunt Lute Books, 1987. 53-64.

Barber, Phyllis. "Stories."Frame Work: Culture, Storytelling, and College Writing. Ed. Gary Colombo, Bonnie Lisle, and Sandra Mano. Boston: Bedford, 1997. 42-49.

California State University. Fresno General Catalogue 1999-2000.

California State University Public Affairs Office. "CSU Enrollment Increases for Fifth Straight Year." December 8,1999. http://www.calstate.edu/pa/ news/1999/Enroll99.shtml.

Canagarajah, Suresh A. Resisting Linguistic Imperialism in English Teaching. Oxford UP, 1999.

Chiseri-Strater, Elizabeth. "Anna." Signs of Life in the USA. Ed. Sonia Maasik and Jack Solomon. Boston: Bedford, 1994. 635-42.

de Certeau, Michel. The Practice of Everyday Life. Translated by Steven Rendall. Berkeley: California UP, 1984.

Fox, Tom. Defending Access: A Critique of Standards in Higher Education. Portsmouth, NH: Boynton/Cook, 1999.

Gilyard, Keith. Race, Rhetoric, and Composition. Portsmouth, NH: Boynton/ Cook, 1999.

__. "Literacy, Identity, Imagination, Flight."College Composition and Communication 52.2 (December 2000): 260-72.

Heath, Shirley Brice. Ways with Words: Language, Life, and Work in Communities and Classrooms. Cambridge, UK: Cambridge UP, 1983.

Horner, Bruce, and John Trimbur. "English Only and U.S. College Composition."College Composition and Communication 53.4 (June 2002): 594-630.

Jordan, June. "Nobody Mean More to Me Than You and the Future Life of Willie Jordan."Frame Work: Culture, Storytelling, and College Writing. Ed. Gary Colombo, Bonnie Lisle, and Sandra Mano. Boston: Bedford, 1997. 273-87. 
Kutz, Eleanor, Suzy Q. Groden, and Vivian Zamel. The Discovery of Competence: Teaching and Learning with Diverse Student Writers. Portsmouth, NH: Boynton/Cook, 1993.

Perez, Emma. The Decolonial Imaginary: Writing Chicanas into History. Bloomington: Indiana UP, 1999.

Sapiens, Alexander. "Spanish in California: A Historical Perspective." Journal of Communication 29.2 (Spring 1979): 72-83.

Shen, Fan. "The Classroom and the Wider Culture: Identity as a Key to Learning English Composition."Frame Work: Culture, Storytelling, and College Writing. Ed. Gary Colombo, Bonnie Lisle, and Sandra Mano. Boston: Bedford, 1997. 175-85.

Silko, Leslie Marmon. "Language and Literature from a Pueblo Indian Perspective."Frame Work: Culture, Storytelling, and College Writing. Ed. Gary Colombo, Bonnie Lisle, and Sandra Mano. Boston,: Bedford, 1997. 21-30.

Soliday, Mary. "The Politics of Difference: Toward a Pedagogy of Reciprocity." Writing in Multicultural Settings. Ed. Carol Severino, Juan Guerra, and Johnella Butler. New York: MLA, 1997. 261-72.

Stenberg, Shari. "Learning to Change: The Development of a (Basic) Writer and Her Teacher." Journal of Basic Writing 21.2 (2002): 37-55.

Tannen, Deborah. "Teachers' Classroom Strategies Should Recognize that Men and WomenUse Language Differently." From Community to College: Reading and Writing Across Diverse Contexts. Ed. Jeff Sommers and Cynthia Lewiecki-Wilson. New York: St. Martin's, 1996. 458-63.

Unz, Ron K., and Gloria Matta Tuchman. "The Unz Initiative." November 8,1997. http://www.catesol.org/unztext.html. 


\title{
Paradigm Clashes Among
}

\section{Basic Writing Teachers: \\ Sources of Conflict and \\ a Call for Change}

\author{
Ann Del Principe
}

ABSTRACT: Although basic writing has become a strong independent field with professionally sanctioned ways of making knowledge, what Stephen North refers to as "lore" still maintains a strong foundation in the field. This lore is often grounded in the belief in a linear paradigm of learning, and is to some degree fostered by traditional conceptions of basic writers and basic writing teachers. The paradigm clashes between lore and professionally sanctioned knowledge emerge quite organically from the varying background experiences of faculty; but, rather than creating a richly diverse group of pedagogical approaches that enhance the quality of basic writing classes, these paradigm clashes are often obstacles to building strong basic writing programs.

In The Making of Knowledge in Composition, Stephen North discusses the division he saw in 1987 between practitioners and researchers in the field of Composition. According to North, prior to the 1960s academic reform movement, practitioners, writing teachers, had been the locus of knowledge-generation for the field of composition. After the founding of modern Composition, capital C, the new field demanded a knowledge-making process more "professional" and scientific than practitioner inquiry, or lore, as North calls the informally shared beliefs about and practices of teaching writing that circulate among practitioners. Lore and practitioner knowledge were, after this point, discounted as legitimate sources of reliable knowledge about teaching writing.

Although North's description and analysis of the transition from prac-

Ann Del Principe is a full-time English Instructor at Kingsborough Community College, CUNY. She teaches developmental writing and reading as well as courses in composition and literature, and is completing her Ph.D. in English Education at New York University. Her dissertation is a study of how secondary-school English teachers' perceptions of their students' social class influence their teaching decisions. 
titioner-based to researcher-based generation of knowledge in Composition is quite valid for professionally sanctioned knowledge, lore still maintains a strong currency, not only among individual practitioners but in many departments. This prevalence of lore, or what Jeanne Gunner, from a Foucaultian perspective, calls "iconic discourse," among teachers of basic writing, along with the simultaneous professionalization of Basic Writing as a field have resulted in paradigm clashes, significant differences in belief and philosophy, among basic writing teachers. As a faculty member in a community college that offers many sections of basic writing, I have observed significant paradigm clashes among those who teach these classes. The paradigm clashes emerge quite organically from the varying background experiences of faculty; but, rather than creating a richly diverse group of pedagogical approaches that enhance the quality of basic writing classes, paradigm clashes are often obstacles to building strong basic writing programs.

\section{Paradigm A: The Linear Narrative of Writing Ability}

Some teachers, typically non-composition specialists who find themselves teaching writing either full-time or part-time, appear to believe in what I would like to call the linear narrative of writing ability. The linear narrative of writing ability is a story of how writers learn; it goes like this: individual writers begin to write by marking letters, then words, then phrases, then sentences, and then small compositions down on paper. Once writers can write sentences and small compositions correctly, they can move on to more complex skills, such as paragraphing. Having mastered paragraphing, they can move on to writing descriptions and personal narratives. Then, slowly but surely, they can make their way to analysis and research. In this narrative, abilities are acquired sequentially, in what is believed to be a logical, building-block order. Abilities build on preceding abilities, the simpler coming first, the more complex following. At the heart of the linear narrative is the belief that there is, ontologically speaking, a sequence of complexity to verbal acts and the parallel belief that discrete levels of ability correspond to the sequence of complexity.

Further, the sequential perspective does not apply only to mastering correct grammar; the linear narrative makes claims about where different genres fall in a sequence of increasing complexity as well. Although this narrative sequence appears in different incarnations (some beginning with 
personal writing, some with descriptive writing, and others with summary), they have in common the presumption that a particular sequence of genres or rhetorical modes represents an ascending sequence of complexity and skill. One place we can see this clearly is in the hierarchy of "thought patterns" for basic writing classes that Mina Shaughnessy articulates in her seminal Errors and Expectations (288). For the first semester of a basic writing course, Shaughnessy advocates teaching only the first three thought patterns, which are: "this is what happened," "this is the look (sound, smell, or feel) of something," and "this is like (or unlike) this" (257-61). Shaughnessy's formulation implies that generic complexity is lowest in acts of narration, slightly higher in acts of description, and higher still in acts of comparison. Only later in their schooling will basic writing students, according to Shaughnessy, be prepared to theorize about causality, solve problems, paraphrase and quote from other writers, and offer their own opinions or interpretations-thought patterns four through seven, respectively (257-61). In my experience, Shaughnessy's beliefs are echoed in the beliefs of many basic writing teachers currently in the field. Last semester, I worked with a colleague in my department who would assign his basic writers essays that essentially asked them only to summarize the plot of the works of literature they had read for the class. When I asked him why all of the students' papers from his class were elaborate, well-written summaries, he told me that he felt that students at this level needed to demonstrate their ability to summarize well before they could move on to argumentative essays.

Interactions I have had with other basic writing instructors have illustrated the strength their belief in the linear narrative. One event stands out in my memory. A group of basic writing faculty in our department had gathered to look at some sample student essays from a basic writing course. The purpose of our meeting was to discuss the strengths and weaknesses of the student writing in order to come to a consensus as to how to evaluate student writing in the course: What kind of writing should pass? What kind of writing should fail? By chance, some student writing from a course I had taught the previous semester had been chosen as the sample student work we would discuss. Since some of the projects I assign to students in developmental classes differ from those assigned by some of my colleagues in the department, the focus of the discussion quickly turned from the student papers to the way I teach. Many of the teachers in the session remarked positively upon the quality and the quantity of student writing in the portfolios. They expressed shock that I could "get our students to write that 
much," and they were sure that their students would not, or could not, produce such lengthy work for them. The teachers were also impressed that the student writers were clearly doing some text-based research for the essays. My colleagues seemed surprised that I had had time during the semester to teach my students how to do research. They were sure that, because their students were basic writers and had "basic" skills to learn during the semester of developmental writing instruction, they could not ask their students to learn how to do research and the analysis research requires.

Shaughnessy and my colleagues are hardly alone in advocating a generic sequence. In his influential book Teaching the Universe of Discourse, James Moffett suggests teaching genres of writing in the order of their level of abstraction because they correspond loosely to Jean Piaget's developmental schema, even though that schema was based on the cognitive development of children. Piaget believed that different cognitive processes unfold and develop over time. He believed in the concept that development occurred before learning and made learning possible. He thought it was a waste of time and basically bad teaching to introduce a concept or skill that was more advanced than a student's current level of development. Thus, Moffett advocates a curriculum that asks students to record and report present events, narrate past events, generalize about events, and, finally, theorize in that order. We can still see the influence of this in the current-traditional perspective represented in many writing textbooks and syllabi, what David Bartholomae refers to as the "infamous description, narration, exposition, persuasion" (86). How many popular college composition textbooks move from the personal narrative to the analytical essay or research paper? Further, how many syllabi for Freshman English or basic writing do the same?

If students are basic writers, often they are asked to write almost exclusively personal essays until they master that type of essay, it being perceived as the lowest on the totem pole of essay writing ability. In a one-onone writing conference, a basic writing student of mine last semester told me that my class was the first time she had been asked to "write like an adult" in a basic writing class. She had taken this particular course three times, each time hoping she would pass on into Freshman English, and each time failing the portfolio and standardized test at the end of the course. When I asked her to describe the types of writing she had been asked to do in previous semesters, she said that she had been asked to write a lot of autobiographical and personal essays. She was tired of them. She did not find these essays intellectually challenging to write or to read. In particular, she was 
tired of re-telling her experience of immigrating to the United States. She had been asked to write about this repeatedly by different teachers over the semesters, and she clearly felt that this type of writing was not helping her to increase her ability to do academic writing.

There are many reasons why the belief in the linear narrative remains so strong among writing teachers. Depending on our ages, we ourselves were very likely taught to read and write based on this narrative model. This was certainly the case for me. I was never asked to develop a research question in grade school; instead, I was asked and expected to describe things in detail and to write broadly focused reports, in which I organized and presented everything the encyclopedias in the library would tell me about a topic. It was as if curiosity about something and the ability to ask a focused question do not, or cannot, develop until a child reaches middle school. Further, once I had finished secondary school and had entered college, description, narration, and reporting were no longer asked of me. Never once was I assigned a project where I had to utilize these other thinking and writing skills that had been so central in my earlier education, as if narrating and describing are such simple tasks that college students would not benefit from doing them.

Perhaps I have misperceived the writing curricula I experienced as a student. Perhaps, as a college student, description, narration, and reporting were vitally involved in the thesis-driven research papers and analytical essays I wrote. Undoubtedly, it is true that I used all of these skills, to some degree, in most writing projects I completed in college. However, just because we can say that analytical writing often involves describing, narrating, and reporting does not mean that we can necessarily say that describing, narrating, and reporting do not each often involve analysis. If we think of any seemingly simple act of narration, we quickly realize that it involves multiple acts of analysis in choosing and creating perspective, pace, form, plot, etc. The same is true of description and reporting. These seemingly simple skills become more and more complex the more attention we pay to them, revealing the artifice in the designation of certain writing skills as "simple" and others as "complex."

Moffett himself warned his readers not to take the sequence of writing tasks he proposed too seriously. He referred to his theory of discourse and his ideal schema for a curriculum as "hallucinations" (54). They are unrealistic because they presume a level of uniformity as to what individual students - and even groups of students - are capable of thinking and writ- 
ing that is simply not accurate. In fact, it is often not the students' ability that determines what types of writing they will be asked to do; it is, instead, often teachers' presumptions regarding what their students should be able to do that determines what they will be asked to do. In describing his findings from a study of writing assignments given in various levels of schooling, Moffett notes:

Certain assignments were not given below a certain grade because the teachers did not want to inflict a debacle on either the children or themselves. Certain upper cutoff points on the abstraction ladder seemed obvious for certain ages. And only a few teachers of very able twelfth graders would even consider assigning an essay that argued a theory from premises, a refusal that was undoubtedly based on good judgement but that may show the ineffectuality of present schooling rather than a developmental limit. (55)

So in order to avoid a "debacle," some students are not even asked to do certain types of abstract thinking in writing. At all levels of schooling, presumptions such as these, about order and appropriateness of skill acquisition, are used by writing teachers to construct curricula.

Teachers who believe in the linear narrative of writing ability conceive of their job as assigning projects that they feel are appropriate for the students' ability level. Thus my colleagues' surprise that I was asking writers who had been deemed "basic" to do projects they thought appropriate for regular freshman or sophomore students. In describing why they would never ask their basic writing students to do the types of projects I had asked them to, these teachers talked about how students were not "ready" for research and complex problem-solving. They often said things like "[the students] can't even write a coherent sentence! They're certainly not ready to try to write a research paper." This comment reveals the belief in the linear narrative of writing ability: the writer who has not yet mastered the "correct" grammar of a sentence is not ready, or able, to move on to a more complex level of writing.

At my college, as at many others, part of our job as basic writing instructors is to play a gate-keeping function; we assess which of our students are ready to go on to the credit-granting Freshman English course, which is a graduation requirement for every student at the college. Teachers routinely use expressions such as "can Suzie handle Freshman English yet?" and 
"I just don't think he could handle that type of work" when making decisions about who they will and will not allow to pass out of developmental writing. These attitudes and beliefs mask the common reality that certain students are in developmental writing not because they are incapable of abstract or complex thinking but because they are second language speakers of English and have not yet mastered Standard English, or because they were never asked or expected to write analytically in their prior schooling and thus do not perform well on tests that ask them to do just that, or because they speak a form of English that is not acceptable to those who score the gate-keeping standardized writing exams.

Teachers' presumptions that basic writing students cannot, in some sense, handle regular academic writing may sometimes find support in older research that suggested that basic writers were cognitively deficient or slow, as compared to their colleagues. In a 1979 article, Andrea Lunsford asserted her then belief that basic writers are cognitively deficient; specifically, she argued that basic writers have not "attained the level of cognitive development which would allow them to form abstractions or conceptions" (38). Similarly, in 1987 Janice Hays presented samples of student writing as support for William G. Perry's conceptual scheme of development in college writers. Hay's article demonstrates one teacher's belief both in cognitive deficiency in basic writers and in the existence of a progressive sequence of writing ability. Today, neither Lunsford nor Hays would likely support their previous positions on basic writers' cognitive deficiencies, but they were hardly alone in presuming some type of cognitive deficiency on the part of basic writing students (Shapiro; Tremblay; Hays). Although research claiming that basic writers are cognitively deficient has since been directly challenged and complicated by other research (See, e.g., Bartholomae and Petrosky; Martinez and Martinez; Lu; Sternglas; and Shor), the idea that basic writers are intellectually less able than their colleagues has a deep history in our field.

\section{Paradigm B: Basic Writers Aren't Basic Thinkers}

A contrasting paradigm that exists among basic writing instructors, especially but not exclusively among those with formal training in the field, is the notion that basic writers, although clearly different from their mainstream counterparts in some ways, are not basic thinkers. In the late 1970 s and early 1980s, researchers were already challenging and revising the cognitive deficiency model. In 1987, Joseph and Nancy Martinez presented a 
study demonstrating that often what we perceive as evidence of less ability on the part of our students is instead evidence of less fluency in Standard American English. They conducted a study of the writing abilities of basic writers versus graduate students using two different writing tasks. Their results showed no significant differences between the two groups' abilities to perform writing and thinking tasks. However, the results did show consistently more mechanical and spelling errors among the basic writers. Is this Moffett's "debacle"? In the discussion of their findings, Martinez and Martinez suggest that it is primarily unfamiliarity with the basic skills of writing Standard American English that classifies students as "basic writers," rather than their deficiencies as logical thinkers and writers. In 1986 Bartholomae and Petrosky published Facts, Artifacts, Counterfacts, in which they present the program of seminar-style Basic Writing courses that they teach and direct, and in which they argue that there is

no reason to prohibit students from doing serious work because they [can] not do it correctly. In a sense, all courses in the curriculum ask students to do what they cannot yet do well. There [is] no good reason to take students who [are] not fluent readers and writers and consign them to trivial or mechanical work in the belief that it [will] somehow prepare them for a college education. It would make more sense, rather, to enroll these students in an exemplary course.... (Preface)

This perspective represents basic writers as literate performers who might be inexperienced in the specific venue of the academy. They don't lack ability, per se; they lack knowledge of conventions and experience with the types of reading and writing the academy requires and rewards.

The theories of learning developed by Lev Vygotsky and Jerome Bruner have influenced much scholarship on basic writing and basic writers. Although they do not openly ground their ideas in Vygotsky's, Bartholomae and Petrosky's basic writing course is sympathetic to Vygotsky's notion that learning precedes development, and not vice versa. Vygotsky's theory advocates what some might call premature instruction. His zone of proximal development (ZPD) refers to the "distance between the actual developmental level as determined by independent problem solving and the level of potential development as determined through problem solving under adult guidance or in collaboration with more capable colleagues" (86). Within a social con- 
text of learning, a person is capable of solving problems and completing tasks that they would not be able to complete in isolation. Further, the only way they will learn to complete these tasks independently is by being asked and expected to accomplish them when they do not yet know how to. Thus, "good learning," according to Vygotsky, is "that which is in advance of development" (89).

Marilyn Sternglass ("Conceptualizing") openly called for a Vygotsky/ Bruner-inspired curriculum in all instruction, especially remedial English instruction. Sternglass's study found that students who came through both ESL and regular basic writing courses did not draw wide-ranging implications from specific texts as much as those students who had been placed directly into Freshman English. Sternglass is cautious to argue that this is not because these students were not able to function at an analytical level. They were perfectly able to do so, but they neglected to perform this ability when writing about literature. Sternglass concluded that "it seems likely that the students coming through the two remedial tracks had not had enough opportunities [in the remedial courses] to consider and practice writing about larger issues and questions posed by instructional materials they had interacted with" (93, brackets mine). Sternglass calls for eliminating the notion of remedial courses as "bridge" courses that teach "basic skills" to students so that they may acquire higher levels of thinking when they join the mainstream courses: "Rather, all these courses, remedial and traditional, should be conceived of as part of a 'spiral curriculum,' to use Bruner's term, in which all kinds of conceptual and linguistic activities are introduced and practiced at each level" (94). If the students in her study had had the opportunity to practice complex "conceptual and linguistic activities" while in remedial English classes, perhaps they would have performed much better on writing tasks demanding complex analysis in regular Freshman English.

But if we assign complex writing and reading tasks, will basic writing students prove capable of making leaps forward in their writing ability, without having been specifically instructed in the seemingly prerequisite levels of writing ability? Nancy Burkhalter asked similar questions when she put Vygotsky's theory of ZPD to the test in a writing class. She investigated whether a group of children could be taught, with adult guidance, to perform a writing task that would have seemed to be beyond their ability level. Groups of fourth and sixth graders wrote two persuasive essays after only three weeks of daily forty-five minute lessons on persuasive essay writing. The students in the experimental group demonstrated greater ability than 
the students in the control group to write persuasive essays. Among those in the experimental group, there were no significant differences in ability by grade level (12). Reflecting specifically on writing curricula, Burkhalter states that "exposure to [persuasive writing] enables students to improve their mastery of it" (16). She stresses that the focus of instruction in writing, and in education in general, should be on how much a person can learn with peer and adult assistance instead of on whether a person meets certain cognitive criteria before instruction ever begins. Moreover, Burkhalter's study challenges us to reconsider the validity of the linear narrative of writing ability.

In my department, I am by no means alone in aiming to teach basic writing in ways that challenge students' writing abilities by requiring them to do what we consider college-level work. I strive to create rich reading and writing environments that enable students to question and analyze in ways that broaden their writing abilities. I try to design my curricula with Bruner's "spiral curriculum" always in mind. While I do not want to frustrate basic writing students by asking them to do work that is completely different from what they are used to writing, I do insist that they do the same types of reading and writing as students in literature electives and other courses. I teach a developmental reading and writing course in which students read Homer's Odyssey and several subsequent versions of, or literary responses to, The Odyssey. Students keep a reading and writing journal, in which they write their own responses to the reading, answer some reading comprehension questions, and write several creative, ungraded pieces that ask them to take different perspectives on the reading. We write a series of four to six essays in this course, each of which is revised a minimum of three times. Although I do provide an assignment sheet for each essay, I do not create the questions or topics for the students' essays. Approximately a week before each essay is due, the students work together, in small groups or with a partner, to create questions they feel have been raised by the literature we have been reading. Although I may help the students reword their questions for clarity or breadth, I do not change the focus of the students' questions. My course is just one example of many in my department in which basic writing instructors enact their belief in the paradigm that says that basic writers should be engaged in truly college-level reading and writing projects. While this perspective has a strong foothold within my department and within our field, it has not displaced the linear narrative of writing ability and the cognitive deficiency model, and belief in any of these paradigms is highly resistant to change. 


\section{Sites of Resistance: Icons and Lore}

Within the basic writing community, certain philosophies and attitudes have become institutionalized into dominant ideologies over decades of research and practice. Employing Foucault's concept of the "icon," Jeanne Gunner divides research in basic writing over the last twenty years into two groups: "iconic" and "critical" discourse. Iconic discourse "reproduces the field according to certain laws, always in relation to the iconic text and figure," while critical discourse "is transgressive, challenging the laws and the icon, and so is received with hostility by the traditional Basic Writing community" (27). She cites Mina Shaughnessy as the iconic figure in basic writing scholarship. Shaughnessy's opinions, and what have come to be positioned as Shaughnessy's opinions, on basic writers and how we should teach them have become the norm within our field. In addition, Gunner examines how Shaughnessy has come to fill Foucault's author function by redefining basic writers as "beginners whose errors have a linguistic logic decodable by the teacher, thus staking out a justifiable place for them within higher education" (28). When Shaughnessy first asserted this perspective on basic writers, this was a new way of understanding them. She effectively authored a field dedicated to studying basic writers, understanding the needs of basic writers, and ensuring the place of basic writing within the university. The field has continued to evolve and generate knowledge, however, and had Shaughnessy lived, her thinking would undoubtedly have evolved as well.

Shaughnessy has also come to be a "founder of discursivity," which means essentially that her text is not just a text on its own but that it has opened up a space for other texts to be produced and reinterpreted. We see this through the myriad citations and uses of Shaughnessy's name, and sometimes actual use of Errors and Expectations, by other researchers in their articles and books. Shaughnessy has come to represent a way of thinking about, and teaching, basic writers that goes beyond what she actually advocated in her own writing. Gunner reminds us that Shaughnessy advocated "formalistic instruction in syntax, punctuation, handwriting, spelling, and vocabulary," which are currently outdated modes of instruction for basic writing (28). Because of the degree to which Shaughnessy's ideas from Errors and Expectations have permeated the field-through formal scholarship and through informal word-of-mouth-of basic writing, practitioners and scholars may not even consciously realize that the way they think about basic writ- 
ing is rooted in Shaughnessy's work. However outdated, Errors and Expectations remains the "originary point of reference for the Basic Writing field" (28).

Through the concept of lore, North describes how beliefs, iconic or otherwise, about basic writing instruction become part of common knowledge among practitioners. Lore is "the accumulated body of traditions, practices, and beliefs in terms of which Practitioners understand how writing is done, learned, and taught" (22). Beliefs enter lore by being "nominated"through a casual comment by the copy machine-by a practitioner. These beliefs do not have to be substantiated by extensive classroom experience or by any careful study or research, although they may be grounded in research. They can be passing impressions, such as "my students seem to do best when I give them specific outlines for how they should write their essays," or fairly institutionalized practices, such as "we should correct our students' grammar errors with a contrasting colored pen." Much of the linear narrative of writing ability is transmitted via lore. Information and perspectives from research can also enter lore, but they are often reinterpreted and fragmented to such a degree that they fit in with the beliefs that already exist in the lore. Shaughnessy's advocacy of formalistic instruction from Errors and Expectations has certainly made its way into lore, but her later work, which complicates some of what she advocated in 1977, has not ( "Selected Speeches and Essays"). Since there is no official, sanctioned, peerreviewed means to regulate the creation of lore as knowledge, there is no institutionalized way to change it.

In fact, lore and iconic discourse resist challenge. Lore cannot be stopped. It is a natural, social part of teaching and can help to create a strong community among teachers. Also, since lore can reinterpret and integrate research findings into its own body of beliefs without disrupting the existing beliefs, it is difficult to change merely by increasing teachers' familiarity with contemporary basic writing research. Similarly, because iconic discourse within the field of basic writing is so strong, any research or opinion that challenges it is received harshly and somewhat defensively. Gunner examines how Min Zhan Lu and Ira Shor, as examples, have opened up the "iconic" Shaughnessy/basic writing institution to criticism. Both Lu's and Shor's JBW articles criticized the icon in different ways, and both met with strong, defensive responses from much of the basic writing community. This same defense of the icon may have motivated some of my colleagues to question and critique my teaching choices. The fact that I do not think basic writers need special, different treatment or that they cannot handle certain 
types of assignments means that I implicitly challenge the iconic position. Certainly some faculty, many of whom have taught in our department for decades, perceive and internalize the iconic discourse that they hear from other faculty and from the institution. They do not even need to be familiar with Shaughnessy's work or other research that supports the iconic position; they simply have to be aware of the lore about what basic writers are like and how they learn.

\section{The BW Teacher's Role}

A belief in the linear narrative of writing ability allows teachers of basic writing to feel certain that our courses are legitimately necessary for our students. If, and only if, there truly are basic writing skills that our students need to master before they would be able to do much more complex and difficult writing and thinking, then our position, as those who teach those basic skills, is vital. We have a meaningful and necessary role in the educational process. In fact, if we are truly teaching basic writers skills that they must have to be able to do college-level reading and writing, one could argue that our job is one of the most vital teaching roles within the university. From this perspective, "the Basic Writing teacher . . . occupies a position of honor. The teacher is constructed as a kind of hero" (Gunner 31).

Gunner defines four "rules of construction" of the teacher-figure according to iconic discourse, the first two of which help us more fully understand some of my colleagues' reactions to my teaching choices and their commitment to their own belief in the linear narrative of writing ability. Firstly, unlike most other faculty in universities, basic writing teachers' "primary credential ... is individual commitment, a sense of mission to teach, initiate, inspire, and defend basic writers" (31). For the basic writing teacher, "knowledge is based in experience and agency in will," rather than being based in scholarly experience or knowledge of the field (31). Thus, many basic writing teachers who are not compositionists have little or no familiarity with scholarship in basic writing or, more generally, composition studies. This is not a problem in iconic discourse because "the teacher-figure works from individual feeling, inspiration, and creativity rather than socially-grounded scholarship," so lack of knowledge of scholarship is not seen as a weakness for a basic writing instructor (31). The qualificationsfor teachers of basic writing are dedication to teaching basic writers and some experience teaching them, or other students. Of course, a major practical reason that many faculty are hired without experience in teaching basic writers 
and/or without scholarly knowledge of the field is simple: numbers. Community colleges must staff an enormous number of basic writing courses, and, unlike many universities, do not have a readily-available fleet of graduate students in Composition Studies, or at least English, to staff the courses. Program administrators interview widely when hiring part-time or full-time instructors, and sometimes hire people with little or limited teaching experience. Fortunately, iconic discourse assures them that the candidate's dedication to teaching and (perhaps limited) teaching experience will suffice. These faculty members' lack of familiarity with research in the field leaves them particularly vulnerable to lore about basic writers and teaching basic writing.

The second of Gunner's rules of construction addresses basic writing curricula. Because knowledge is based in individual experience, "curricula and pedagogies are to be self-made" (31). Unlike many university freshman and sophomore composition programs, which often follow relatively prescribed curricula, basic writing curricula are largely left up to individual instructors to invent. Having worked as an adjunct and full-timer at my college for years, I can attest to the validity of Gunner's observation. In my department, many different course descriptions exist for our various basic reading and writing courses, but instructors are given a great deal of latitude. Approaches, texts, and activities are recommended, but no actual curricula are distributed to teachers. Even if there were specific and directive curricula, although this might lead us to imagine that there was consensus on appropriate curriculum and pedagogy, in fact there would exist a wide variety of quite different versions of each course. Because faculty members are working from very different paradigms about basic writers and how they learn, the courses these faculty actually teach manifest their divergent beliefs. When we compound this self-reliance with Gunner's first rule, we realize that many teachers of basic writing courses are not grounding their own curricula and instruction in current basic writing scholarship; instead, they are basing their decisions on their sense of what basic writers need, which is largely informed by the linear narrative of writing ability. Furthermore, many teachers of basic writing use strictly current-traditional or grammar-based methods that basic writing scholarship challenged and revised years ago; however, the scope of basic writing programs coupled with the vast numbers of contingent faculty who staff them make it almost impossible to manage this clash of paradigms effectively. 


\section{Breaking Down Walls}

Often these clashes in teaching style and philosophy remain tacit, or if consciously noticed, are considered too significant and deeply ingrained to work on resolving. We do our basic writing students a disservice by accepting paradigm clashes among faculty and not actively trying to break down, or at least scale, the walls between different belief systems. Although paradigm clashes will likely always exist to some degree in any large department, many steps can be taken to try to acknowledge, understand, and work towards resolving these differences. Assuming that many basic writing courses will continue to be taught by faculty who have not been formally trained as composition teachers and scholars, institutions could help increase teachers' familiarity with professional scholarship in basic writing. Taking into consideration North's warning that lore can withstand even scholarship that directly challenges its beliefs, it would be neither sufficient nor effective simply to distribute scholarship to teachers and expect it to have any effect on their thinking or practice. Instead, there should be department-sponsored opportunities for dialogue among faculty. Within the context of these dialogues, points of difference in philosophy and practice should be noticed and focused on. The goal of this type of dialogue would not simply be to instruct or inform teachers about scholarship, but rather to encourage teachers to think of themselves as a group of learners who are learning together through discussions of readings and practices.

Obviously, the primary obstacles to offering this type of faculty development are time and money - free time during which an already overworked faculty can participate, and money to organize the faculty development and to encourage participation. In my department, like many others, we try to do the best we can with limited resources. We offer some workshops and talks during each semester on topics in teaching composition, but attendance at these workshops is entirely voluntary. Not all faculty members are able to attend or choose to attend. If institutions could offer significant financial incentives to faculty to participate, or could require participation in a quantity of discussions, this would help encourage real dialogue. We also use norming sessions, in which faculty meet to come to consensus on how to evaluate sample student essays, to foster faculty development. During the work of "norming," we sometimes have the opportunity to discuss some elements of our practice or problems we are running into in our classes. While this is a good idea, it simply does not offer the 
concentrated time and scholarly context necessary for conceptual issues in teaching to be seriously discussed.

If colleges do not have the resources to run the types of discussion groups described above, they could at least institute ongoing faculty discussions of research and practice in a less formal manner. Faculty could be invited to come together to discuss research in the field and aspects of their own practice that they are consciously working to improve. This kind of conversation would help departments begin to break down the walls created by paradigm clashes that exist among basic writing faculty. The iconic image of the basic writing teacher as a rugged individual whose teaching is based on lore and field experience is counter-productive to our work as a field. There is some irony to the fact that the majority of basic writing courses may be taught by faculty who are unfamiliar with basic writing scholarship. We must take steps to open dialogue among faculty with differing beliefs about teaching basic writing in order to build better community and improve our collective practice.

\section{Works Cited}

Bartholomae, David. "Teaching Basic Writing: An Alternative to Basic Skills." A Sourcebook for Basic Writing Teachers. Ed. Theresa Enos. New York: McGraw-Hill, 1987. 84-103.

__ , and Anthony R. Petrosky. Facts, Artifacts, Counterfacts: Theory and Method for a Reading and Writing Course. Upper Montclair, NJ: Boynton/Cook, 1986.

Bruner, Jerome. The Process of Education. 1960. Cambridge, MA: Harvard UP, 1977.

Burkhalter, Nancy. “Applying Vygotsky: Teaching Preformal-Operational Children a Formal-Operational Task.” United States Department of Education. Office of Educational Research and Improvement. Research Report ED 379208, 1994.

Gunner, Jeanne. “Iconic Discourse: The Troubling Legacy of Mina Shaughnessy." Journal of Basic Writing 17.2 (1998): 25-42.

Hays, Janice N. "The Development of Discursive Maturity in College Writers." A Sourcebook for Basic Writing Teachers. Ed. Theresa Enos. New York: McGraw-Hill, 1987. 480-96.

. "Socio-Cognitive Development and Argumentative Writing: Issues and Implications from One Research Project." Journal of Basic Writing 7.2 
(1988): 42-67.

Lu, Min Zhan. "Redefining the Legacy of Mina Shaughnessy: A Critique of the Policies of Linguistic Innocence.” Journal of Basic Writing 10.1 (1991): 26-40.

Lunsford, Andrea. "Cognitive Development and the Basic Writer." College English 41.1 (1979): 38-46.

Martinez, Joseph G. R., and Nancy C. Martinez. "Are Basic Writers Cognitively Deficient?" Paper presented at the Annual Meeting of the Western College Reading and Learning Association, Albuquerque, NM. 9-12 April 1987.

Moffett, James. Teaching the Universe of Discourse. Boston, MA: Houghton Mifflin, 1968.

North, Stephen M. The Making of Knowledge in Composition: Portrait of an Emerging Field. Portsmouth, NH: Boynton/Cook, 1987.

Perry, William G., Jr. Forms of Intellectual and Ethical Development in the College Years: A Scheme. 1968. San Francisco: Jossey-Bass, 1999.

Piaget, Jean. Six Psychological Studies. Trans. A. Tenzer, D. Elkind. New York: Vintage Books, 1964.

Rose, Mike. "Remedial Writing Courses: A Critique and a Proposal." A Sourcebook for Basic Writing Teachers. Ed. Theresa Enos. New York: McGraw-Hill, 1987. 104-23.

Shapiro, Nancy S. "Rhetorical Maturity and Perry's Scheme of Cognitive Complexity." Paper presented at the Annual Meeting of the Conference on College Composition and Communication, $36^{\text {th }}$ Annual, Minneapolis, MN, 21-23 March 1985. ED255935.

Shaughnessy, Mina. Errors and expectations: A Guide for the Teacher of Basic Writing. New York: Oxford UP, 1977.

. "Selected Speeches and Essays of Mina Pendo Shaughnessy." Journal of Basic Writing 3.1 (1980): 91-119.

Shor, Ira. "Illegal Literacy." Journal of Basic Writing 19.1 (2000): 100-112.

. "Our Apartheid: Writing Instruction and Inequality." Journal of Basic Writing 16.1 (1997): 91-104.

Sternglass, Marilyn. Time to Know Them: A Longitudinal Study of Writing and Learning at the College Level. Mahwah, NJ: Lawrence Erlbaum, 1997.

_. "The Need for Conceptualizing at All Levels of Writing Instruction." Journal of Basic Writing, 8.2 (1989): 87-98.

Tremblay, Paula Y. "Writing Assignments for Cognitive Development." College Composition and Communication 37.3 (1986): 342-43. 
Paradigm Clashes Among Basic Writing Teachers

Vygotsky, L.S. Mind in Society: The Development of Higher Psychological Processes. Eds. Michael Cole, Vera John-Steiner, Sylvia Scribner, Ellen Souberman. Cambridge, MA: Harvard UP, 1978. 


\title{
"You Probably Don't Even Know I Exist": Notes from a College Prison Program
}

\author{
Jane Maher
}

ABSTRACT: Although much has been written recently about prison "writing" in general (Wally Lamb's Couldn't Keep It to Myself, Mark Salzman's True Notebooks), far less has been written about the efforts and challenges involved in helping prisoners. In this case, females in a maximum-security prison in Westchester County, New York, learn the kind of writing skills required to succeed in college. While the inmate-students' writing skills in the pre-college program are similar to those of basic writers on the "outside," the students' lack of confidence in their ability and their belief that they are not "worthy" of a college education often present challenges (and rewards) that I begin to examine in this article.

When I was asked in 1997 to teach a basic writing course to the female inmates at the Bedford Hills Correctional Facility in Westchester, New York, I knew a lot about teaching writing, but I knew absolutely nothing about prisons, prisoners, their need for post-secondary education, or the way their past personal and educational experiences would impact on their ability to succeed in college.

Now, I sometimes think I know far too much: about the conditions that contributed to the circumstances that brought many of the women to prison in the first place; about the pain and angst they suffer upon being separated from their families, particularly their children; about the poor (or nonexistent) educations they received before arriving at prison; about the inequality of sentencing based on race and class; about the diseases that ravage these women and their families as a result of poverty; about the way that drugs can destroy two, even three generations of the same family; about the way many people in society view these prisoners ("Aren't you afraid of

\footnotetext{
Jane Maher is a professor in the Basic Writing Program at Nassau Community College, Garden City, New York. She is the author of four biographies, including Seeing Language in Sign: The Work of William C. Stokoe (Gallaudet University Press), and Mina P. Shaughnessy: Her Life and Work (NCTE). She is the Director of Special Programs in the Bedford Hills college program, which is funded by the non-profit Women's Prison Education Partnership.
} 
them?" is the question I am most often asked about my work); about the way that politicians support harsh sentencing to win public approval, from the draconian but ineffectual Rockefeller drug laws to the decisions handed down day after day by parole boards, keeping even non-violent offenders behind bars until they "max" out; about the fact that Pell and TAP grants for prisoners were withdrawn in 1995 in order to save the taxpayers' money, despite the fact that the amount being spent on post-secondary education for prisoners was only a minuscule portion of the total budget-about six cents of every ten program dollars (Kunen 38); about the fact that this country imprisons more people than any other country in the world-half a million more than Communist China (Schlosser 52); about the fact that hundreds of thousands of the almost two million prisoners in the United States will be released in the next ten years having received little or no training or education to prepare them for reentry (Schlosser 58); and most disturbing of all, about the fact that these conditions, coupled with scores of others, often leave the prisoners feeling frustration, rage, helplessness, or a sense of worthlessness.

But I also know that good things can happen in prison, as contradictory as that sounds. One of them, in fact, is the non-profit Women's Prison Education Partnership college program, one of several programs that exist at Bedford Hills because of the extraordinary courage and wisdom of Elaine A. Lord, the recently retired superintendent. In the midst of the "get tough on crime," "race to incarcerate," "three strikes and you're out," "send them back to prison for minor parole infractions," "build more prisons than schools" mentality that has overtaken the United States, Lord has steadfastly focused on programs that will help the women prepare for release. "Empowerment is what I aspire to bring to the women," she said in a recent interview. "I struggle with whether this is a valid concept in a prison, but the women report that they felt safe at Bedford, sometimes for the first time in memory, and that they were able to learn and think" (Wilson 25).

For the past 20 years, Bedford Hills has been a model facility for those who believe that prisons can actually be places where inmates are able to benefit from education, training, and counseling. As one of the college students wrote, "Bedford is the place that cured me of the diseases that brought me here."

Evidence of this curing environment is everywhere. The college program's computing and learning center (Bedford is one of the few prisons in New York State where inmates are permitted to have access to com- 
puters) is located in the basement of the facility's administration building, right next door to the children's center, where inmates can spend time visiting with their children. In the children's center, women learn to read so they can make tapes to send to their children; take courses in child care and development (overseen by volunteers from Bank Street College); contact their children's social workers, care givers, and teachers; and learn parenting skills. Women who are pregnant when they are arrested (provided they satisfy certain requirements) can keep their babies with them in the prison nursery for 18 months-one of the few prisons in the United States where such a program exists (and the model for prison nurseries in several European countries). Members of the local chapter of NOW (the National Organization for Women) meet regularly to conduct book discussion groups with some of the inmates; lawyers from Columbia Law School hold seminars with the women to help them understand their cases and their rights of appeal; members of church groups provide much-needed services to the womenfrom preparing food for visiting family members (who often travel for hours with young children via public transportation) to collecting clothes for the women to wear when they are released. The women are able to participate in the Puppies Behind Bars program, in which they train puppies for eventual service as guide dogs for the disabled. Although Bedford Hills looks very much like a prison, with rows of razor wire surrounding its perimeter, the presence of black Labrador puppies learning to walk up and down staircases and children crawling around the playroom can make it seem like a very human place at times. The women receive mandatory counseling for drug and alcohol addiction, participate in family violence prevention programs, sexual abuse workshops, and learn about anger management. During the summer, through the Host Family Program, inmates' children reside with local families so they can spend entire days for a week or two with their mothers at the prison. The inmates are required to participate in literacy programs-ABE (Adult Basic Education) and GED (General Educational Development) - sponsored by the Department of Correctional Services, and the GED passing rate at Bedford Hills is far higher than in most U.S. prisons. This success is the result of an aggressive and determined effort on the part of New York State Department of Corrections Deputy Superintendent of Education, Dr. John Nuttall, to improve the quality of instruction and participation in these classes.

In fact, the policies and practices at the prison are so progressive that in the late 1980s, long before doctors and other medical personnel fully 
understood the causes and treatment of AIDS, the inmates at Bedford Hills had, with the full approval and cooperation of the superintendent, set up a program whereby they could learn and then teach each other about the disease, care for each other, and educate people both inside and outside; in fact, the inmates collaborated in writing a book about the ACE (AIDS Counseling and Education) program, in which they described their experiences as they joined together to overcome the fear and ignorance that existed among the inmates and the corrections officers as more and more inmates were diagnosed with HIV and AIDS.

A volunteer at the prison who had also worked at several other prisons once told me that the women at Bedford Hills actually look different than prisoners at other facilities: they walk with their heads held higher, make eye contact, engage in conversation in a way that indicates a sense of pride and self-worth. "Bedford Hills is a prison, of course," she noted, "but it is less of a prison because the women are still being encouraged to think, to change, and to hope."

Despite this environment, however, when I arrived at Bedford Hills in the late 1990s, the college program was barely functioning. When TAP (New York State Tuition Assistance Program) and federally financed Pell grants were withdrawn in 1995, the thriving, full-time college program administered by Mercy College ceased to exist, along with 350 other prison college programs across the United States (despite an aggressive lobbying campaign mounted by college administrators and educators who produced reams of evidence showing the benefits to society of post-secondary prison education). At Bedford Hills, the impact of losing the college program was immediate and severe. Several inmates were tantalizingly close to earning their degrees, and they were crushed by the prospect of never completing their college education. Many of the inmates had painstakingly completed all of the non-credit requirements and had finally begun to earn college credits. "My son and I were going to start college at the same time," one of the inmates recalled, "and I knew that it was so hard for him on the outside that when I told him I wasn't going to be able to go to college, it would take away his incentive-it was the one time in his life that I had been a positive role model to him, and now I didn't even have that to offer him." Use of the library dropped, as did interest in the GED program. There was an increase in suicide attempts. Fighting on the living units increased. And the officers noticed that the women who had formerly participated in study groups or tutored other students were now struggling to find a way to 
replace college. "The card games, boring television, street talk, gettin' it on did not satisfy them anymore," one of the officers noted.

Within two months of the withdrawal of college, several of the inmates asked the superintendent if they could try to find volunteers who would be willing to reinstate the college program without using public funds. As usual, the superintendent not only agreed, she helped to identify and contact potential resources. A community organizer and long-time prison volunteer, Thea Jackson, responded with great enthusiasm-and efficiency. Through her friendship with Dr. Regina Perrugi, who was President of Marymount Manhattan College at the time, she was able to organize a consortium of several metropolitan-area colleges that agreed to provide instructors and other resources, with Marymount Manhattan functioning as the degree-granting institution. It was a grand schemebut a risky one. There was no precedent, and no money. Would people make donations to a program that had just lost public funding based on the decisions of their own elected officials?

Running a college program in a maximum-security facility is difficult under the best of circumstances: security rules prohibit the use of fax machines, the Internet, e-mail, calculators, palm pilots, cell phones. All visitors must be approved by the Department of Correctional Services in Albany before they are permitted to enter the facility (a process that can take up to two months), and, in addition, all approved visitors must have their name placed on a gate clearance each and every time they enter the facility - a time-consuming practice that eliminates any possibility of a professor just "dropping in" to confer with students. All academic supplies must be approved in advance and inspected upon arrival-no workbooks with metal spiral bindings (the mentally ill inmates might use them to self-injure). The student-inmates can only move from place to place within the facility at certain times and under certain conditions. Instructors can only communicate with the inmates during class time or during prearranged appointments in the learning center. Given the way the inmates' days are scheduled and the availability of classrooms, college courses can only be offered in the evenings-from 6:30 until 9:30-at the end of very long days for both the inmate-students and the professors. The prison is located in one of the most beautiful (and expensive) areas in lower Westchester County, a place where few college professors can afford to live; therefore, professors who volunteer to teach often have to travel relatively long distances to get to and from the prison. Department of Correctional 
Services' rules prohibit volunteers from sharing personal information with the inmates in order to protect the volunteers' safety, but this practice is often antithetical to the open and questioning climate that exists in college classrooms; professors must refrain from using personal examples to illustrate, to model, to inspire the students.

Negotiating these conditions was difficult enough when Mercy College had a full-time administrator in place. (Mercy's program was a model among prison college programs, and Mercy College continues to support the "new" program with extraordinarily generous donationseach semester, they cover the cost of four or five courses.) When the "private" college program returned, particularly during its first semester of operation, when it had not yet raised any money, when it had no office supplies, when it had no facilitator, it was a logistical nightmare.

Yet we managed, not only because of the enthusiasm of the students, the faculty, and the community organizers, but because of the good will of the facility's staff. Of course, there was the occasional officer who wondered why prisoners should be entitled to a free college education when they could not afford one for themselves or in many cases for their children, but, for the most part, the officers understood what the politicians and the public who voted for these politicians had not. As one officer explained, "I see these women, girls really, no more than 17 or 18 or 19 or 20 , coming back again and again because of drugs or the street life, and I know that they came back because they went home the same way they came-with no education, no job prospects. Pimps, drugs, abuse, prison-it's a cycle. Maybe college can break that." The officers even help the women with their homework. "I think this essay is ready for our class publication," one of the students wrote in a note to me. "I moved the second paragraph to the end. At first I didn't agree with you but the officer tonight read it and he said I should move it, he sees your point."

College can break the cycle. As the new college program gained stability, Dr. Michelle Fine, a renowned sociologist from the City University of New York (CUNY) Graduate Center and a former volunteer in the program, conducted (with several student inmates as co-researchers) an intensive qualitative and quantitative study showing that the recidivism rate of female offenders decreases in direct proportion to the amount of college education they receive in prison (Changing Minds).

When I first began to teach in the college program at the prison in 1997, however, I was not aware of many of these facts and circumstances. 
In fact, the reason I was asked to participate was that although those students who had already participated in college were doing okay (in fact, they were working harder than ever, reinvigorated by the fact that college had returned), the new students, those who had no college experience and particularly those who had recently entered the prison system, were struggling mightily: extremely low scores on the admissions examinations, poor attendance, low confidence, inappropriate classroom behavior, high attrition. I recognized and identified these students immediately. My years of experience teaching basic writing first at Kingsborough Community College, CUNY, as an adjunct, and then at Nassau Community College as one of the founders of the Basic Education Program, my graduate work in composition studies at New York University, my research and writing of the biography of Mina Shaughnessy - all had prepared me to identify and help those students who, as Shaughnessy once said, "come to us at the last moment of their formal education, expecting, needing to encounter teachers who will finally make a difference" (qtd. in Maher 309).

But as I came to know these students, I began to realize that although they were similar in some ways to those students on the "outside" (a term the inmates use) who are required to take non-credit courses, they were different in ways that would affect and impact my teaching-and their learning. Shaughnessy had talked about the "last moment"; I began to feel that these students were beyond that already precarious point in their educational careers, perhaps even in their lives.

These differences are difficult to describe and were, at first, difficult to identify. In most cases, the students' reading and writing skills were slightly better than those of the students whom I taught on the outside. I was not quite sure how to account for this because as I began to get to know the "pre-college" students (a term that the inmates themselves began to use to refer to the students in non-credit classes), I realized that their educational experiences had been truly dismal, either because of the poor quality of the schools they had attended or because their lives had been so chaotic that they had not attended school very much, if at all. I later began to think that their stronger literacy skills were a result of the fact that the primary means of communicating with those on the outside was through letter writing; phone calls are prohibitively expensive and many family members are unable or unwilling to visit. The exception to this was the Latina students, most of whom earned their GEDs in Spanish at the prison and thus were unable to pass the admissions examinations in English, 
despite the implementation of ELL (English Language Learning) workshops.

Despite these better skills, however, many of the pre-college students had little or no confidence in themselves, and little or no sense of the connection between their poor educational experiences and their current status. In contrast to the resistance or even bravado sometimes exhibited by my students on the outside- "I didn't take the admissions test seriously"; "These non-credit classes are a waste of my time"; "Why do I have to pay money when I'm not earning credit?"-many of the women who placed into the pre-college courses at Bedford Hills seemed to believe that they had relinquished all rights to any kind of attention at all, much less a college education. This sense of worthlessness was reflected in one of the first notes I received from an inmate interested in enrolling in the college program, the note from which I have taken my title. "You probably don't even know I exist," the note began:

You are a very busy person and may not have time for me. And I don't know if I can come to college at all. I just earned my GED at Rikers and my scores were good, at least that is what my counselor said, but I have never been a good student and I have no money to pay for fees or books. I never thought I was smart at all because I didn't get good grades and everyone said it was okay when I dropped out of high school at a young age and pregnant. If I can't come to college I understand, but do you have college books that I can read and memorize so I can educate myself a little more and keep up with my peers on the unit?

Other notes and conversations confirm this sense of not belonging, of a lack of entitlement. I have saved these notes, first in the hope of using them to write a book about the program (when there is time for such a project), but now because they are very special to me, both as a writing instructor and as a human being. They represent and reflect the challenge I and others in the program face: to help these women overcome a pervading sense of not belonging, of not being worthy of attention, of not having a voice, a place, a future. For those who wonder what became of the children described in Jonathan Kozol's Savage Inequalities, I fear I have the answer in this two-inch-thick packet of notes I have accumulated over the past seven years. I remember clearly the early Saturday morning about five years ago when I began to read the responses my students wrote in 
reaction to Cedric Jennings' struggle to succeed at Brown University after having attended one of the worst high schools in the nation (reported by Ron Suskind in A Hope in the Unseen). I had expected the women to relate to Cedric's struggles, to sympathize with the inequities he endured, to realize how difficult it was for him to grow up with his father in prison. Instead, they said he was lucky: "He has a roof over his head, a mother who works. He has never been shot or stabbed. That's more than my kids have."

One student recalled being referred to as "fat house" through the first two years of high school; she dropped out, became a prostitute, and was eventually sentenced to ten years for a drug-related crime. "I was being abused at home sexually, but then going to school I didn't fit in so I went to the streets. And now here I am. I got my GED after two tries. Now let's see if I can do college. I won't tell my family I'm trying for college they'll just tell me I'm stupid and wasting my time."

Another student wrote, "I did not like the movie [The Sweet Hereafter]. It brought back memories. Do not show that movie to us anymore. I'm not the only one."

At one of the first sessions of one of the first basic writing courses I taught at Bedford Hills, I asked the women to tell me what kind of writing they did in prison and what kind of writing they needed help with. Their responses were further reminders of the differences between them and the students whom I usually taught: My students on the outside occasionally remind me that as soon as they complete their college writing requirements, they will never have to write again. The women in my course at Bedford Hills, however, told me about writing projects that had profound and permanent effects upon them.

Writing a formal letter to the family that would take care of my baby when she left me and the [prison] nursery program to go into foster care. I read it to her in the middle of the last night we were together. I leaned over her crib knowing she did not understand the words but the family will know the words have meaning. In the letter I asked the family to love her for me. I did not need help with that letter. It came from my heart. Mistakes were not of concern to me just that the family knew this was a loved and wanted baby. 


\section{"You Probably Don't Even Know I Exist"}

Breaking the news to my grandmother that I am HIV positive. She does not understand that there is medication today. I have to tell her so she can have my children tested.

Writing to my children's teachers. They are going to see the envelope saying the prison and the inmate box number. I don't want to bring more shame on my children but I have a right to know how they are doing. I want to know if they are getting extra help that they need.

I want to be in college and need writing skills for that. Please help me. My way out of this life is an education. I have to start over when I get out. Be where nobody knows me. I will have to read job ads, find an apartment, find my children.

I am going to write about my educational failures so others can be warned-no they are not my failures. I was told to take vocational classes because I am a woman. Because I am black. Because I had no one to look out for me.

The women explained in their notes that they must write to judges, court-appointed lawyers, social workers, case workers, doctors, correctional services personnel, even funeral directors. And in almost every note to me, they wished that they could write better, more clearly, "say it right" so that attention would be paid. Perhaps the most painful notes for me to read were those that explained that the woman had not done any writing recently for they had no one to write to.

Approximately $45 \%$ of the women at Bedford Hills suffer from mental illness, and some of these women place into the pre-college program. "I'm going to write to request that my mental meds be reduced so I don't fall asleep in class or while doing my homework."

Other notes reflect the overwhelming factors working against these students as they begin college, often at the same time they are beginning to serve their prison sentences. The students whose reading and writing skills (and self-confidence) are weakest are the ones who are most overwhelmed by the circumstances that arise as they begin their long periods of incarceration. (Because Bedford Hills is a maximum-security prison, only women with sentences longer than eight years are usually sent 
there. Ironically, this is an advantage in terms of the college program because it affords the women-who are able to take two courses per semester-enough time to earn a two-year and sometimes a four-year degree.)

I have been here for two months after almost a year in the county jail. I can't concentrate on school right now and I am going to drop out and return my books. I read the first pages of homework over and over but can't seem to realize what it says. I can only think of the pain I have caused my mother. And can her health hold up under the stress of caring for my children and her own children still at home (my two brothers).

Often, as I make the long drive home from the prison at 9:30 at night, I wonder how even the strongest women function under the circumstances they encounter in prison. While I am frequently amazed at the way my students on the outside manage to juggle the responsibilities of family, work, and school, these issues seem more manageable than the circumstances faced by the inmates. When I first began to volunteer at the prison, I believed that the women would be able to concentrate on college in a way that students on the outside could not. After all, they had "time" on their hands and they had few other responsibilities. I quickly realized what a serious (but common) misconception this was. The women, like all New York State inmates, are required to participate in work, study, and counseling programs that take up most of their day. Those who work in the mess hall, for example, have shifts that begin at 5 a.m. They serve hundreds of inmates, scrub huge pots, stir gallons of oatmeal or soup or some other hot, heavy liquid. "I am coming late for class," one inmate wrote, "not because I don't want to be there, but because I have to shower after my shift in the mess hall. I smell nasty and don't want to come to class like that."

Those who work in the laundry are on their feet all day, working with steaming hot equipment in rooms that sometimes reach 115 degrees in the summertime. The "pay" averages from 15 to 30 cents an hour. Those women who do not get any help from outside in the form of money or packages of food or small pre-approved items must use this money to pay for personal hygiene products that are not provided by the system. (I learned about this when one of the officers expressed sympathy for one of the students whom he described as "wearing state, eating state." In prison, 
as on the outside, there are the haves and have-nots.) The students in the college program are required to pay tuition of five dollars per semester, and although we make it clear that students who cannot afford to pay this amount do not have to do so, very few students ask for an exemption.

The inmates are separated from their families, particularly their children, and this causes them the greatest pain and worry. (Seventy-five percent of the women in the pre-college program are mothers, more than half with children under the age of six.) These mothers carry pictures of their children, and they keep small personal items that belong to their children with them all the time: hair barrettes, tiny plastic action figures, a stone found on a path during a visit.

In an article that appeared recently in The New York Times, Sara Rimer explained the conditions that Elaine Bartlett, a former Bedford Hills prisoner and college student, found on the day she was released and returned home to her four children:

[Bartlett] had fantasized about the welcome party her family would hold in their apartment in a housing project on the Lower East Side, where they have moved in her absence. ... What greeted her instead was a disaster scene. "There was no food in the refrigerator, no toilet paper," she said. "The toilet seat was broken-the sink was full of dirty dishes. There were roaches and mice running around. The ceiling was black with dirt...." Ms. Bartlett had returned home to find that her family had created its own prison in a housing project, and that she had been living better behind bars than the rest of the family outside. (Rimer B1)

Research has shown the high correlation between poverty and illness, and nowhere is this more evident than in the lives of these inmates, many of whom are HIV positive or suffer from diabetes, cancer, or high blood pressure. The grandmothers, who often raised them, are now raising their children-and the inmates feel anguish and guilt as they watch the toll such responsibility takes: heart disease, asthma, diabetes are common, and deadly. When a grandmother dies, the inmate must then either identify another relative who can take over the care of her children or look on helplessly as the child enters the foster care system. There is an expression among counselors who work with prisoners: "When a man is released from prison, he returns to a woman who has been caring for his children, holding his house together. When a woman is released from prison, she returns to 
a woman who has been caring for her children, holding her house together."

Many of the women were sexually or physically abused as children and fear that their children will be abused; in addition to the other permanent and devasting effects of such abuse, research has shown that sexual abuse has a detrimental effect on a student's confidence and ability to learn. Many of the inmates were addicted to drugs and/or alcohol when they were arrested and are struggling to overcome these addictions. Although the prison offers highly effective programs, one of the greatest challenges the security officers face is making sure visitors are not carrying in drugs for the prisoners-they are sometimes hidden in the diapers of visiting infants.

Prison living conditions are difficult, even frightening. Bedford Hills may be a model facility in terms of programs, progressive treatment, a staff that supports and encourages growth and change through programs, but it is still a prison. Inmates live in close proximity to other inmates, many of whom are mentally ill, hostile, or violent. The loss of personal choices and freedoms is difficult to adjust to, particularly the state-issued uniforms; highly restricted use of telephones; loss of privacy (phone calls can be monitored and mail can be read); control over every aspect of day-to-day life, including the type of make-up that can be worn, the time one eats, sleeps, works, and moves from one location to another; pat-frisking by male officers (a practice that is being challenged in court); the potential for harsh punishment such as placement in the solitary housing unit (SHU), or loss of other privileges for infractions that often seem arbitrary or capricious; being set up, robbed, or attacked by other inmates. One of the counselors once told me that it takes up to three years for inmates to fully accept the fact that they are "doing time." They often hold out hope-against serious odds-that their appeals will be successful; they are often so ill or run down by the life they had been leading that they are not at first aware of the severity of their sentences. As one of the college students said in an essay about her life before and after prison:

I can't believe I am saying this, but I am almost grateful for prison. If I weren't here, I'd be dead. I had no job and had not had one for seven years. I had lost my kids to crack and I mean lost, I did not even know where they were. I was committing more crimes while awaiting trial for previous crimes. I was in an abusive relationship 
that was worse than the one I had left two years before. I didn't know who I was anymore, and I didn't care. A counselor once tried to tell me that I had to come to terms with the sexual abuse I had suffered in my childhood, that I was self medicating, but I remember thinking he had no idea of the deal-did he think I could just pick myself up and go to therapy? Would that be before or after my pimp came to collect?

The younger student inmates, the ones most likely to place into the pre-college program, face an even more difficult time adapting. As Superintendent Elaine Lord noted in an interview:

The younger women are more unruly, and they haven't learned how to adapt to prison routines yet. They expect the prison to adapt to them, just like kids on the streets think they have the world in their hands. They can be like teenagers in high school-focusing on relationships and how they look to peers. They are not thinking much about the future; they live in the now. If they have a long sentence, they really can't conceive of it. A 40- or 50-year sentence to someone who has only lived 17 or 18 years is meaningless. They are more concerned with meeting other young women coming off the intake bus that they might have met at the county jail. They are concerned about how they look. They engage in relationships and experiment with homosexuality because they are fiercely interested in all things sexual-just as many teens in the community are. Too often they see the world as a place where they have to take what they can or be left without. We forget that at this age all teens are still growing and learning how to be people. (Wilson 23)

One of those teens was dismissed from the college program because she was "out of place"; in other words, she had told her unit officer that she was coming to the school building to work on a college writing assignment, but instead she sneaked off with her girlfriend. During this time, she got involved in a fight and seriously hurt someone. "I'm returning my books," she explained. "I can no longer attend college because of a distraction. It's been nice knowing you. Don't worry about me." Her work habits and performance had been exceedingly poor. Her attitude had been so defensive and at times hostile that she was one of the few inmates with whom I felt uncomfortable, even afraid; the other inmates expressed similar 
feelings about her. I "lose" students on the outside frequently, but losing students in prison is different. There is truly nowhere else for them to go. That closing line, "Don't worry about me," was, I believe, pure bravado. I am convinced that there has not been anyone in that inmate's life who worried about her, and that is why she was so tough, so defensive, so unable to get along with others. I worried enough to negotiate a one-year suspension rather than a dismissal (again, through the kindness and support of prison officials).

And there is my favorite note of all-actually two notes-from the same inmate. I had just returned a set of essays to my students. After about five minutes Robin (not her real name) approached my desk and placed her essay in front of me. By the time I had finished commenting on her essay, I had written more than she had, and clearly my comments had offended her. I looked down and saw that she had printed, in large letters, the following words: “Are you dissin' me?" The other students were still reviewing their essays, so I had a chance to respond: "No, Robin, I'm not dissin' you, I'm trying to help you become a better writer so you can succeed in this course." When we had a chance to talk (out in the hall, away from the other students, but within earshot of an officer), I discovered that Robin had completed three years of high school, but during those three years, she had not written one essay, "not even one page, not even one paragraph, not even one word," yet she had passed all of her English courses. Robin was furious that I had "messed up" her essay "with all that shit you wrote. If you don't like my writing, just give me a bad grade."

At the end of that semester, after scores of such "discussions" since Robin questioned every one of my comments and corrections, she managed to pass my course and the exit examination and qualify for credit-bearing classes. On the last night of classes, Robin approached my desk in much the same way she had early in the semester; the similarity was clearly intentional. This time, she placed the following note on my desk: "Jane, I really appreciate your suggestions and I also appreciate your position in my life. I am intrigued by learning. I look forward to fighting every Monday. Teach me, Jane, teach me."

It is notes like these that I concentrate on as I go about the task of teaching writing to the women in the pre-college program at Bedford Hills. I am not naïve enough to think that the problems I've listed (and there are scores of others) will either go away of their own accord or be solved entirely by the inmates' participation in college courses, and I am not naïve enough 
to believe that the students whom I teach are in prison because of conditions entirely beyond their control. And I am constantly consumed with the fear that I and other incredibly hard-working volunteers will not be able to continue to raise the funds we need to keep this extraordinary program going. When the program was in such dire need of funding that we were not sure we would be able to continue for another semester, one of the inmates wrote to me saying "I know how hard it is, but please don't take college away. My only way out of this life is an education."

If I have learned anything as a result of my work in the college program at Bedford Hills, it is that what we do matters, helps, makes things better. And that writing - as hard as it is to teach and learn-is a skill that will not only help the women succeed in their college courses, it will help them succeed in negotiating prison life and life after prison in a way that few other skills will.

I will end not with a note, but with an entire essay written by Kecia Pittman, a 27-year-old former pre-college student (she earned her associate's degree last year and was the salutatorian) who "hit" the streets when she was 13 (her mother could not care for her because of a drug addiction), spent the next six years in a series of foster homes, and is serving her third term at Bedford Hills. This essay was written at my request after she sent me a note saying I could never understand her so she wasn't going to do a particular writing assignment. After scores of conversations and writing conferences, I agreed that perhaps she was right, but she would never know unless she tried. I also asked her not to imagine me as a reader, but to imagine "other" readers who knew nothing about her but who sincerely wanted to understand what she wanted and needed to say.

Writing about my college experience is not easy to do because my psyche is wrapped up in it. My personal experiences, my inadequacies, my ideas about success, my family history, and who I am now as opposed to who I was before, influence and shape how I feel about college. Do not get me wrong: I love my education. However, I think and exist in an agonizing dichotomy of future optimism and past failures. My apprehensions are fed by my anger and my hunger for a better life. I look for a release from a gripping past that will threaten me as soon as I step out of these gates.

Because of college, this is the first time in my life I am trying to discover who I have become. Writing for the purpose of sharing 
this discovery with people I have never met is so difficult because it is so impersonal. Yet strangely, something inside me wants the reader involved in this process. I want to convey the complexities of revelations and conclusions as they evolve. I shall make every effort to write as if the reader is here with me having an intimate conversation as I churn out ideas about who I am for the very first time.

I do not think the impact college has had on me can be fully understood until I define who I was and still am to some degree. I am the only child of a single-parented African-American home. I went up to the eighth grade. Somehow at age 13, I failed my mother or she failed me because I've been in the street ever since. There are a lot of hurts and disappointments swimming around like sharks in my memory. I survived the group homes and the streets. Decisions were made on pure impulse and they resulted in actions based solely on the inexperience of my 13-year-old mind. I am not feeling sorry for myself, but can you imagine the baggage I carry? There were never trophies or certificates indicating that I was doing the right thing. Instead, my rewards came in good-time sensations and short-lived comforts, no matter how dangerous. Nobody loved me enough to tell me to do different.

Even now I still feel like that 13 -year-old child. Surviving. In college, I've learned that since I'm still alive, I've beaten the odds. I survived, yes, but I was never in one home long enough to submerge myself in the healthiness of school, friends, class trips, favorite teachers or prom night. It saddens me to write this because I never was forced to think of my life this way. The loss of my education and everything it represented early in my life contributes to the dichotomy of my fear of failure crowding in on my desire to be optimistic. Although my college experience does not render me automatically healthy, it does make me feel as if someone threw me a lifeline as an alternative to a pre-established pattern of thinking.

Education, no matter how late obtained, has a way of destroying the misconceptions that I lived by. I loved myself but in a submissive and low self-esteem kind of way. I now think that this stunted my ability to avoid many defeatable situations. My psyche was always saying, "I can't, I don't know how." In 1997 I met a college professor here in BHCF who literally turned red in his urgency to teach me otherwise. His main goal was to convince that thing inside me that it was not my fault, something true but so foreign to my understanding of life, of myself. 
The one hard truth for me is that although I have made my way to prison three times, this is the first time I will emerge educated. The dichotomy of optimism and fear of failure is a mixture of this time's college experience and last time's unsuccessful releases. The truth is, college has spliced in new ideas to help me consider old perceptions. My understanding of life and my approach to problem solving has been altered in a way that leaves me vulnerable to new heights of optimism for the future but also fears of failing without the excuse of ignorance. The truth is that I now acknowledge myself as an intellectual human being and a symbol of strength by overcoming the odds. Not even the most successful among you may have survived what I have survived.

However, lurking in the depths of my mind is the low selfesteem warning me of who I was and not to trust who I am becoming. I feel like I am sitting between two worlds. You must understand: I have not had a chance to know what this experience will mean when I return to the old boulevards, the ratty tenements, the crackhead avenues. I am mostly concerned that the animalistic drive to survive will take over when I hit the streets again.

I am learning at this moment. I am, for the first time, actively and knowingly dialoging with myself for the purpose of truly figuring out who I am. I like sharing this with you, whoever you are. I am intellectualizing my experience. The fact that I could not have done this before is a revelation popping into my head as I write. I never had a reason to ask myself who I am, never thought my mind could check itself out. Optimism! That is what positive use of my prison time means. I am not involved in the nothingness of doing time. The day-by-day drifting of meaninglessness and depression that can consume a person. As I write I am engaged in an assignment for my professor, Jane Maher, but right now I am discovering college's impact on me. Right now at this writingmoment.

College gave me a need and a reason to believe I could do something with my life even though there are so many things going against that belief. I am so afraid and so hopeful at the same time. My mind feeds on the collision of past and future. Without college there was nothing to hope would change. Without my past there would be nothing to look forward to changing. I am angry at my situation, yet in prison I could waste this anger on so many things 
that will never change. However, instead I use my anger to drive my academic achievements. My memories of failure keep me fearful enough to see optimism as the only possible route out of an indescribable, madness, (meaning anger and insanity).

College has been a bridge over some very troubled waters. The impact it has had on me is most of what you have just read. The things I cannot convey are made of words not yet formed in my head to explain. They will come. However, without college nothing would have been needed to be said, because nothing inside of me would have changed.

\section{Works Cited}

Changing Minds: The Impact of College in a Maximum Security Prison. Ed. Michelle Fine et al. 24 May 2004 〈http://www.changingminds.ws〉. Kozol, Jonathan. Savage Inequalities. New York: HarperCollins, 1992.

Kunen, James S. “Teaching Prisoners a Lesson." The New Yorker 10 July 1995: 34-39.

Lamb, Wally, and Carolyn Adams Goodwin, with women of the York Correctional Institution. Couldn't Keep It to Myself: Testimonies from Our Imprisoned Sisters. New York: HarperCollins, 2003.

Maher, Jane. Mina P. Shaughnessy: Her Life and Work. NCTE: Urbana, IL, 1997.

Rimer, Sara. "At Last, The Windows Have No Bars." New York Times 29 Apr. 1995: B1.

Salzman, Mark. True Notebooks. New York: Knopf, 2003.

Schlosser, Eric. "The Prison-Industrial Complex."The Atlantic Monthly. Dec. 1998: 51-77.

Suskind, Ron. A Hope in the Unseen: An American Odyssey from the Inner City to the Ivy League. New York: Broadway Books, 1999.

Wilson, Tracy Payne. “A Warden's View: Interview with Elaine Lord." Finding Our Place Special Issue 4 (2003): 19, 22-25. 


\section{NEWS AND ANNOUNCEMENTS}

\section{The Conference on Basic Writing-Award for Innovation}

The Conference on Basic Writing's Award for Innovation recognizes writing programs for innovations that improve educational processes for basic writers through creative approaches. CBW wants to recognize those college and university programs that are implementing new or unique ways to improve the success of their basic writing students. Is your program doing something especially useful and effective in terms of assessment, placement, pedagogy, curriculum, community outreach, etc.? If so, please nominate yourself for the 2005 CBW Award for Innovation.

For complete information, please see http://www.asu.edu/clas/ english/composition/cbw/Inny_1.html

\section{Call for Papers: Exposing Myths About Literacy, Language and Culture}

Rhetoric, composition, writing, and literacy scholars have long spoken of the need to take our arguments public in order to gain better support for our work, both within our own institutions and in our local and national communities. Unfortunately, contemporary debates about student writing and language and literacy education are not driven by scholarship in our field, but by popular texts (i.e., Cultural Literacy, The Closing of the American Mind, and The Language Police) and media reports, which are often politically partisan or simply ill-informed. Johnny Can Write: Exposing Myths About Literacy, Language and Culture will inform a general audience of educated parents, students, educators, administrators, policy makers, and citizens about our theories and practices that complicate and challenge circulating texts and common perceptions about literacy and language education.

We seek authors for our proposed edited collection who can distill complex arguments into lively and engaging texts for a non-academic audience.

Possible topics may include (but are not limited to): the rhetoric of decline; the teaching and meaning(s) of grammar; literacy and technology; literacy and identity; the relationship between testing and writing; ideology and curriculum; (the origins and (in)stability of) the canon; the history of English studies; tensions between literature and rhetoric; multiculturalism; the 
role of politics in the English classroom.

Send abstracts (500-word max.) or essays (20-page max.) by February 1, 2005 to David Gold (dpg@umd.umich.edu) or Liz Rohan (erohan@umd.umich.edu), Dept. of Humanities, University of Michigan-Dearborn, Dearborn MI 48128. Please include a cover letter with brief bio.

\title{
Symposium: Second Language Writing Instruction in Context(s): The Effects of Institutional Policies and Politics
}

The 4th Symposium on Second Language Writing will take place from September 30 to October 2, 2004, at Purdue University, West Lafayette, Indiana, USA. Invited speakers will include:

\author{
Danling Fu, University of Florida \\ Ilona Leki, University of Tennessee \\ Sarah Weigle, Georgia State University \\ Jessica Williams, University of Illinois at Chicago.
}

The theme for this year's symposium is "Second Language Writing Instruction in Context(s): The Effects of Institutional Policies and Politics." While the majority of work done in second language writing addresses instruction, the focus of much of this scholarship is on what happens in the classroom as opposed to how the institutional contexts outside the classroom shape instructional practices. To help remedy this imbalance, this symposium will focus on institutional polices and politics and how they influence classroom practice. We refer here to policies on assessment, placement, credit, class size, course content, instructional practices, teacher preparation, and teacher support and to politics in terms of the relationships and interaction between second language writing professionals and their colleagues at the program, department, school, college, and university levels and beyond.

Presenters will explore how institutional policies and politics affect instructional practices. The Symposium will also provide many opportunities-both formal and informal-to interact with presenters as well as other second language writing specialists.

\section{Special Event: Graduate Student Conference on Second} Language Writing.

In addition to the regular two-day symposium, we will host a graduate student conference on Thursday, September 30. We hope many people- 
both graduate students and experienced second language writing specialists-will participate in this event, which aims to bring together the next generation of second language writing specialists.

The Symposium on Second Language Writing is a biennial professional conference that brings together teachers and researchers who work with second- and foreign-language writers to discuss important issues in the field of second language writing. More information about past symposia is available at: http://symposium.jslw.org/. 


\section{Journal of Basic Writing}

Boyd Printing Company Inc., 49 Sheridan Ave., Albany, NY 12210

Phone: (800) 877-2693; Fax: (518) 436-7433; www.boydprinting.com

\section{Subscription Form}

$J B W$ is a semiannual publication. Subscribers receive two issues, Spring and Fall, yearly.

- Send me a one-year subscription, individual $\$ 15.00$

- Send me a two-year subscription, individual $\$ 28.00$

- Send us a one-year subscription, institutional $\$ 20.00$

- Send us a two-year subscription, institutional $\$ 38.00$

- Bill us (available only to institutions enclosing a purchase order)

- Foreign postage (all non-U. S. addresses) \$10.00 per year

Total amount of payment enclosed \$

Please make checks payable to Journal of Basic Writing

Name

Address 


\section{Journal of Basic Writing -- Order Form: Back Issues (1975-2003)}

Back issues are $\$ 7.50$ each. Issues listed below are still in print. Pre-1986 issues bear theme titles. Abstracts for articles published since 1996 are available at http://www.asu.edu/clas/english/composition/cbw/jbw.html
Vol. 1 No. 1 Error
No. 2 Courses
Vol. 3 No. 2 Training Teachers of Basic Writing, Part
Vol. 4 No. 1 Basic Writing \& Social Science Research, Pt I
No. 2 Basic Writing \& Social Science Research, Pt II
Vol. 5 No. $2 \quad$ Fall 1986
Vol. 6 No. 1 Spring 1987
No. 2 Fall 1987
Vol. 7 No. $2 \quad$ Fall 1988
Vol. 8 No. $1 \quad$ Spring 1989
No. $2 \quad$ Fall 1989
Vol. 9 No. $1 \quad$ Spring 1990
No. 2 Fall 1990
Vol. 10 No. $1 \quad$ Spring 1991
Vol. 11 No. 1 Spring 1992
No. 2 Fall 1992
Vol. 12 No. 1 Spring 1993
No. 2 Fall 1993
Vol. 13 No. $1 \quad$ Spring 1994
No. $2 \quad$ Fall 1994

\begin{tabular}{lll} 
Vol. 14 & No. 1 & \multicolumn{1}{c}{ Spring 1995 } \\
& No. 2 & Fall 1995 \\
Vol. 15 & No. 1 & Spring 1996 \\
& No. 2 & Fall 1996 \\
Vol. 16 & No. 1 & Spring 1997 \\
& No. 2 & Fall 1997 \\
Vol. 17 & No. 1 & Summer 1998 \\
& No. 2 & Fall 1998 \\
Vol. 18 & No. 1 & Spring 1999 \\
& No. 2 & Fall 1999 \\
Vol. 19 & No. 1 & Spring 2000 \\
& No. 2 & Fall 2000 \\
Vol. 20 & No. 1 & Spring 2001 \\
& No. 2 & Fall 2001 \\
Vol. 21 & No. 1 & Spring 2002 \\
& No. 2 & Fall 2002 \\
Vol. 22 & No. 1 & Spring 2003 \\
Vol 22 & No. 2 & Fall 2003
\end{tabular}

Number of issues $X \$ 7.50=\$$

(Make checks payable to Journal of Basic Writing)

Name

Address

Mail to: Journal of Basic Writing, Boyd Printing Company, Inc., 49 Sheridan Ave., Albany, NY 12210 


\section{How is this publication thinking about the future?}

By becoming part of the past.

This publication is available from

ProQuest Information and Learning in one or more of the following ways:

- Online, via the Proquest' information service

- Microform

-CD-ROM

-Via database licensing

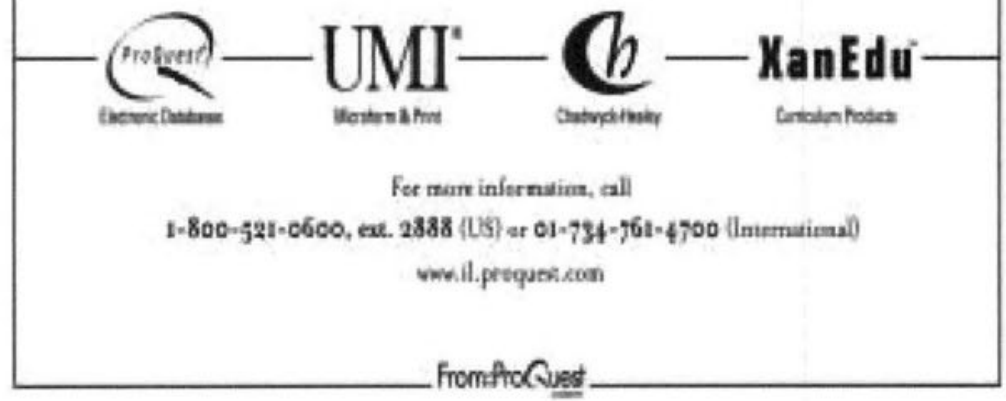




\section{Journal of Basic Writing}

Department of English

Kingsborough Community College, CUNY

2001 Oriental Blvd.

Brooklyn, NY 11235

NONPROFIT

ORG.

U. S. POSTAGE

PAID

ALBANY, N.Y.

Permit No. 31 